Journal of Agricultural, Environmental and Veterinary Sciences

Volume (5), Issue (4): 30 Dec 2021

P: $22-40$
مجلة العلوم الزراعية

والبيئية والبيطرية

AJSRP

ISSN: $2522-3364$
المجلد (5)، العدد (4): 30 ديسمبر 2021م

ص: 22 - 40

\title{
Addition of Ginseng (Withania Somnifera) To the Diet and Its Effect on Productive Performance for Broilers Raised with Two Different Densities
}

\author{
Anwar Mohammed Al-hamed \\ College of Agriculture and Forestry || University of Mosul || Iraq
}

\section{Anwar Hamdoun Al-Taie}

Nineveh Agriculture Directorate || Ministry of Agriculture || Iraq

Abstract: The study was conducted to find out the effect of adding ginseng root powder (Withania somnifera) at $(0,1.5$ and 3.0) $\mathrm{g} / \mathrm{kg}$ under two densities of breeding (12 and 17) birds $/ \mathrm{m}^{2}$ on performance, economic indicators. Chicks were raised from the age 1 day-42 and distributed to the treatments at the second week in $T_{1}: 12$ bird $\backslash m^{2}+0 \%, T_{2}: 12$ bird $\backslash m^{2}$ $+1.5 \%, \mathrm{~T}_{3}: 12 \operatorname{bird} \backslash \mathrm{m}_{2}+0.3 \%, \mathrm{~T}_{4}: 17 \mathrm{bird} \backslash \mathrm{m}^{2}+0 \%, \mathrm{~T}_{5}: 17 \mathrm{bird} \backslash \mathrm{m}^{2}+1.5 \%, \mathrm{~T}_{6}: 17$ bird $\backslash \mathrm{m}^{2}+0.3 \%$. The statistical analysis showed that there was no significant difference in density in body weight, weight gain, relative growth, feed conversion factor, production index, production coefficient, while the density was $12 \mathrm{birds} / \mathrm{m}^{2}$ superior in consumption The feed density of 17 birds $/ \mathrm{m}^{2}$ gave a higher productivity in $\mathrm{kg} / \mathrm{m}^{2}$ compared to $12 \mathrm{birds} / \mathrm{m}^{2}$. The addition of ginseng did not affect the weight gain, relative growth, conversion factor, index, production coefficient, productivity yield in $\mathrm{kg} / \mathrm{m}^{2}$, while there was a superiority of adding (1.5 and 3.0) g of ginseng compared with no addition in live body weight and in Feed consumption and production factor and in the effect of the interaction there were no significant differences in the weight gain, growth, feed consumption, evidence and production factor, while we note that the interaction( $12 \mathrm{birds} / \mathrm{m}^{2}+1.5$ gm ginseng) gave the highest body weight and a significant improvement in the feed conversion factor for the addition of (1.5 and 3.0) gm under the influence of breeding density $17 \mathrm{birds} / \mathrm{m}^{2}$ and the productivity yield exceeded $\mathrm{kg} / \mathrm{m} 2$.

Keywords: broiler, density, ginseng, performance, economic indicators

$$
\begin{aligned}
& \text { إضـافة الجينسنغ (Withania somnifera) إلى العليقة وتأثيره في الأداء الإنتاجي } \\
& \text { لفروج اللحم المربى بكثافتين مختلفتين } \\
& \text { أنوار متحمد الحامد } \\
& \text { كلية الزراعة والغابات || جامعة الموصل || العراق } \\
& \text { أنوار حمدون الطائي } \\
& \text { مديرية زراعة نينوى || وزارة الزراعة || العراق }
\end{aligned}
$$

\footnotetext{
المستخلص: أجريت الدراسة لمعرفة تأثير مسحوق جذور الجينسنغ (Withania somnifera) بإضافة ( 0و 1.5و 3.0) غم/ كغم عليقة

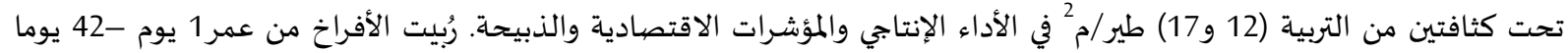

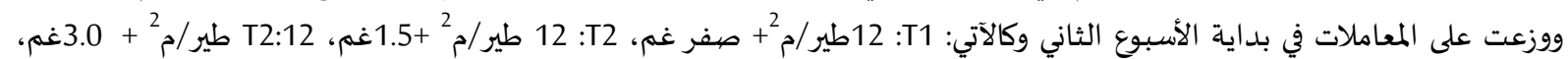

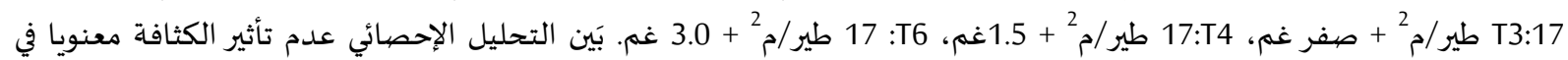

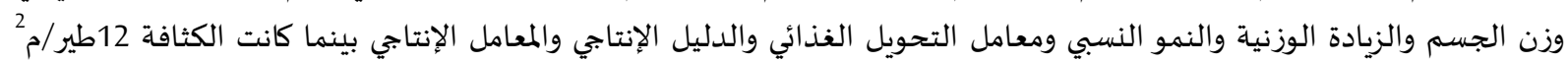




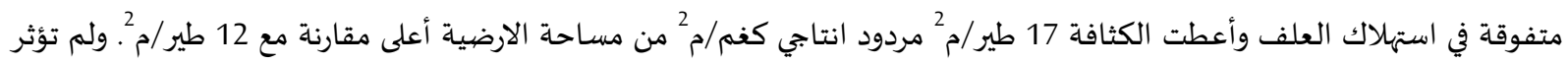

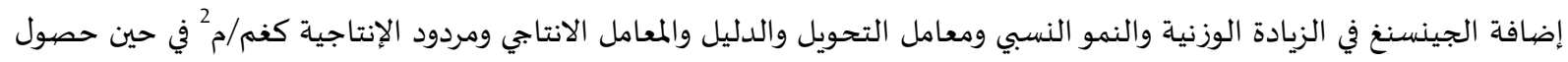

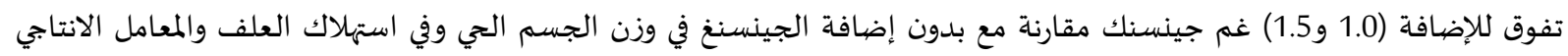

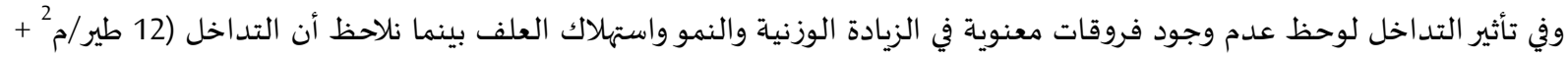

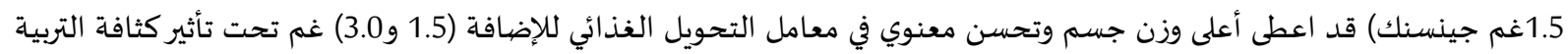

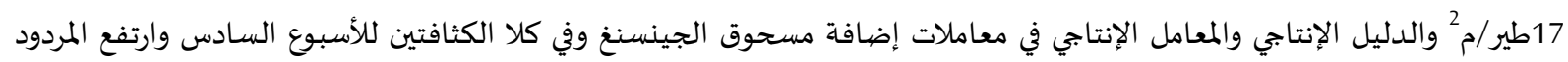

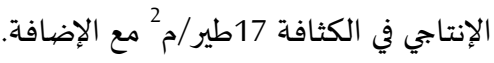

الكلمات المفتاحية: فروج اللحم، الكثافة، الجينسنغ، الأداء، المؤشرات الاقتصادية.

المقدمة.

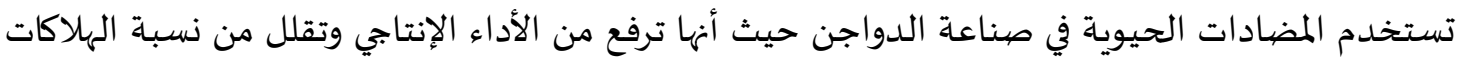

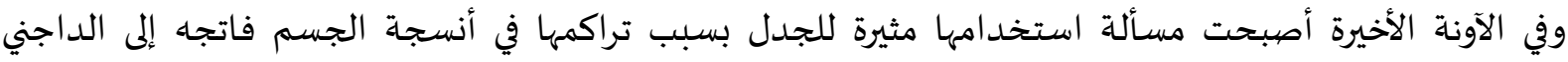

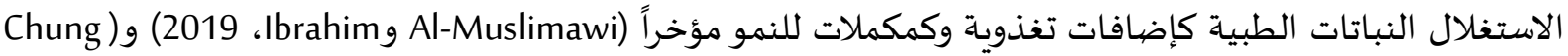
وآخرون، 2014) ( وآخرون، 2010) وللحفاظ على توازن البيئة الداخلية وتعزيز النمو وتحسين الأداء (الحامد

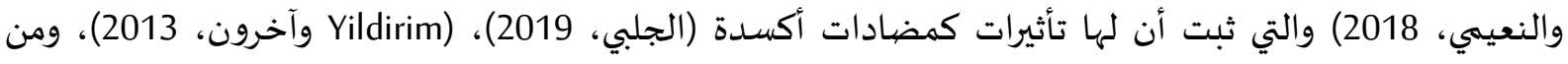

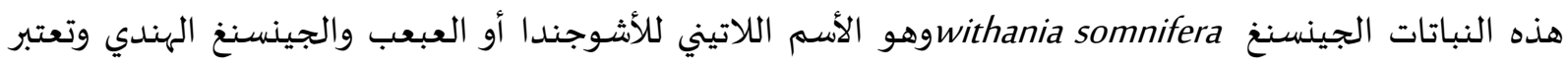

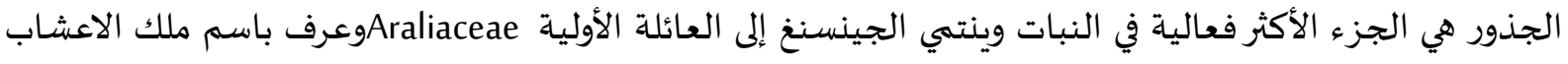

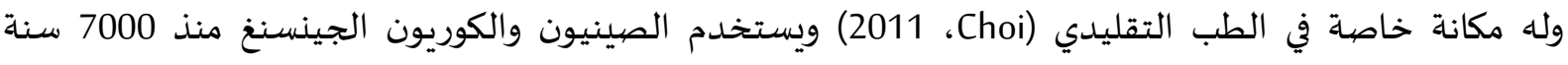

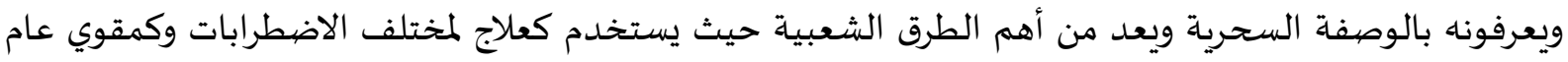

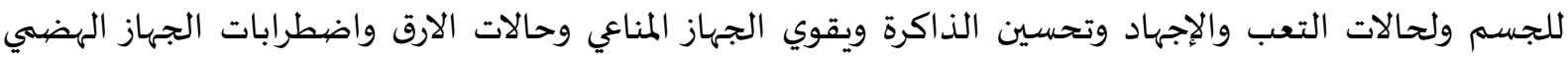

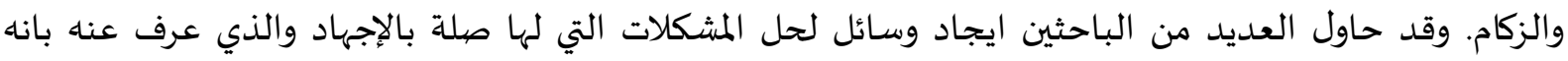

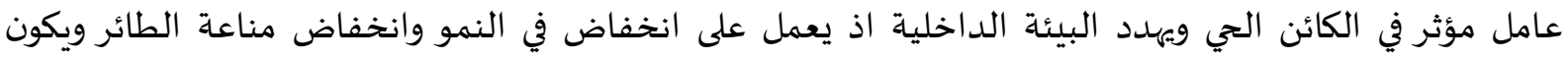
السبب الرئيسي في زيادة تكوين الجذور الحرة والذي يحدث اضرار في الخلايا من خلال أكسدة الدهون وتكوين بيروكسيدة الدهن بالإضافة إلى تأثيره على المادة الوراثية للخلية وله علاقة تادئ بالإجهاد التأكسدي (محممد وآخرون، 2013) و(عبد المجيد، 2013) وتقديم هذه الحلول من خلال استخدام النباتات الطبية التي تزيد من مقاومة الإجهاد

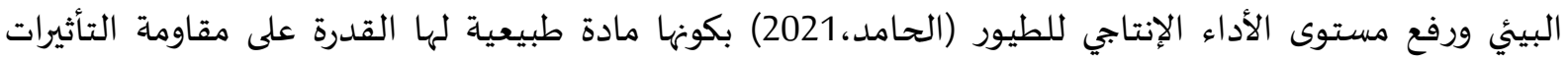

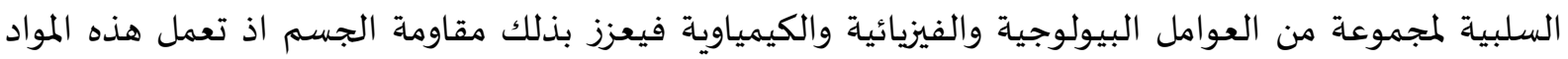

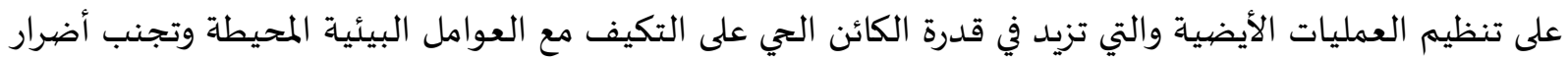

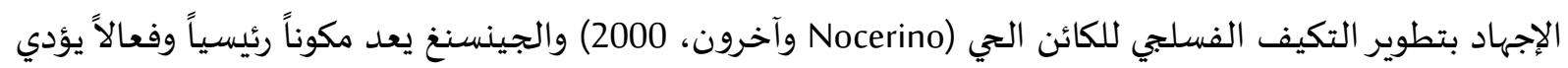

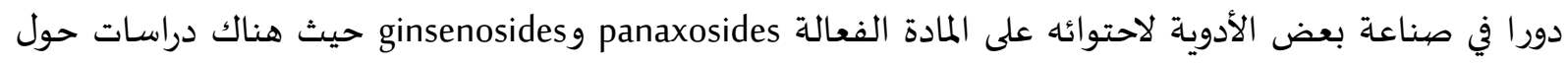

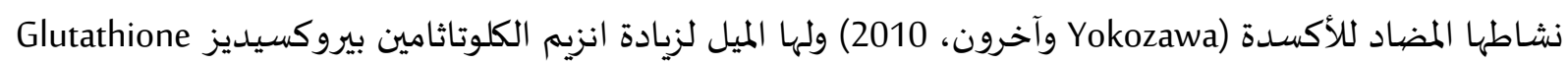

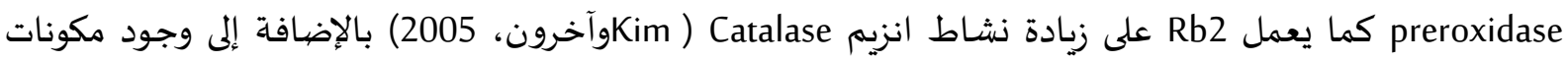

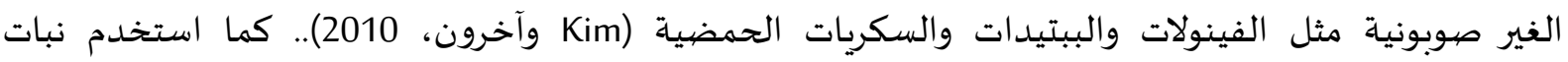

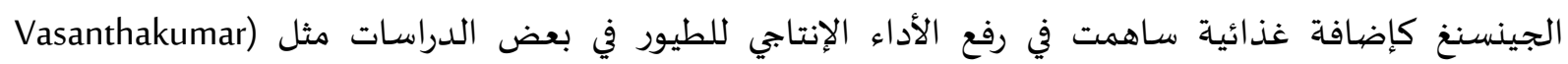

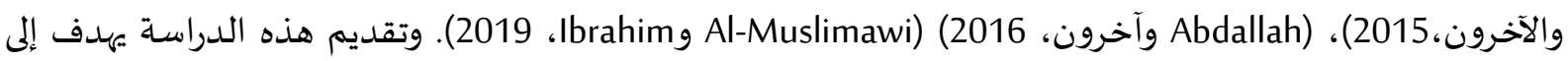


استخدام مسحوق جذور الجينسنغ في علائق فروج اللحم كوسيلة إدارية تغذوية لتحسين الأداء الإنتاجي في ظروف الإجهاد الناتج عن الكثافة.

\section{المواد وطرائق العمل.}

أجريت هذه الدراسة في حقل الدواجن التابع لقسم الثروة الحيوانية - كلية الزراعة والغابات في جامعة

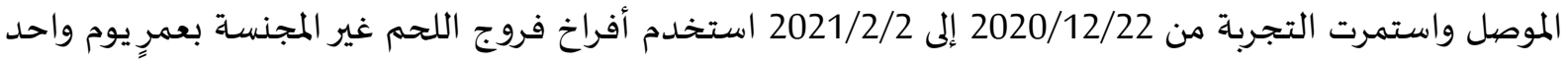

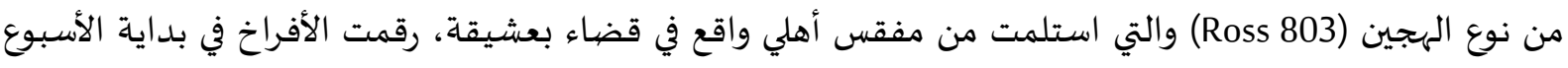

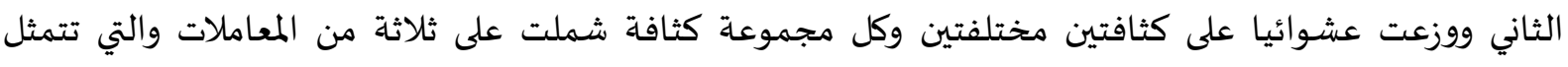

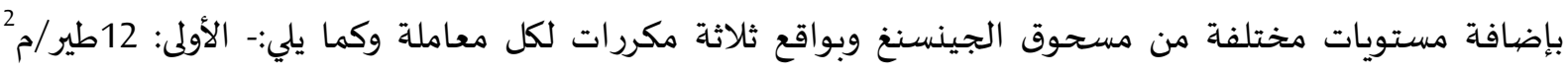

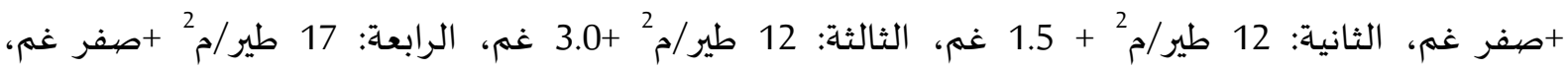

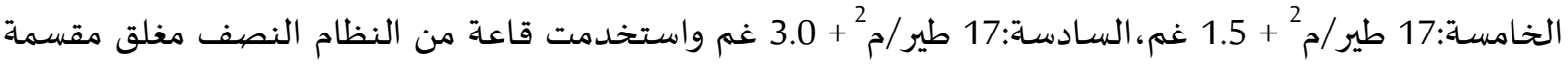

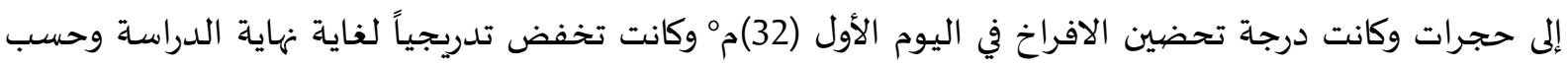

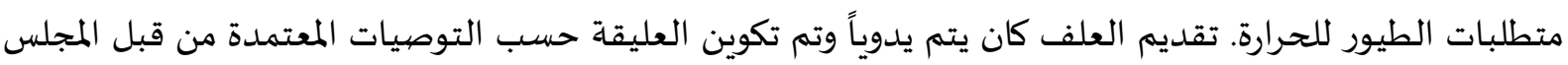

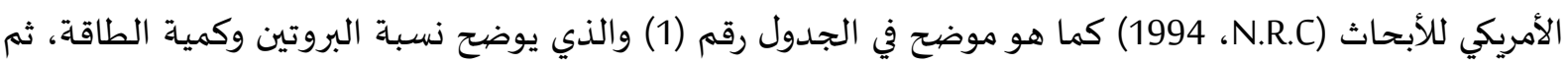
اضيف اليها مسحوق جذور الجينسنغ الصينية المنشأ وبالنسب المعتمدة لكل المدول معاملة. الجدول (1) النسب المئوية لمكونات العليقة

\begin{tabular}{|c|c|c|}
\hline عليقة النمو\% & عليقة البادئ\%\% & المواد العلفية \\
\hline 51 & 60 & ذرة صفراء \\
\hline 40 & 28 & كسبة فول الصويا \\
\hline 5 & 11 & مركز بروتين \\
\hline 3 & - & زبت نباتي \\
\hline 0.7 & 0.7 & 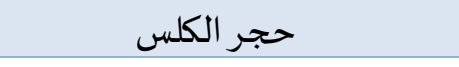 \\
\hline- & - & فوسفات ثنائي الكالسيوم \\
\hline 0.3 & 0.3 & ملح الطعام \\
\hline 100 & 100 & المجموع \\
\hline \multicolumn{3}{|c|}{ التحليل الكيميائي المحسوب } \\
\hline 24.08 & 22.00 & البروتين الخام \% \\
\hline 3012.8 & 2918.9 & طاقة ممثلة(كيلو سعرة/كغم) \\
\hline \multicolumn{3}{|c|}{ 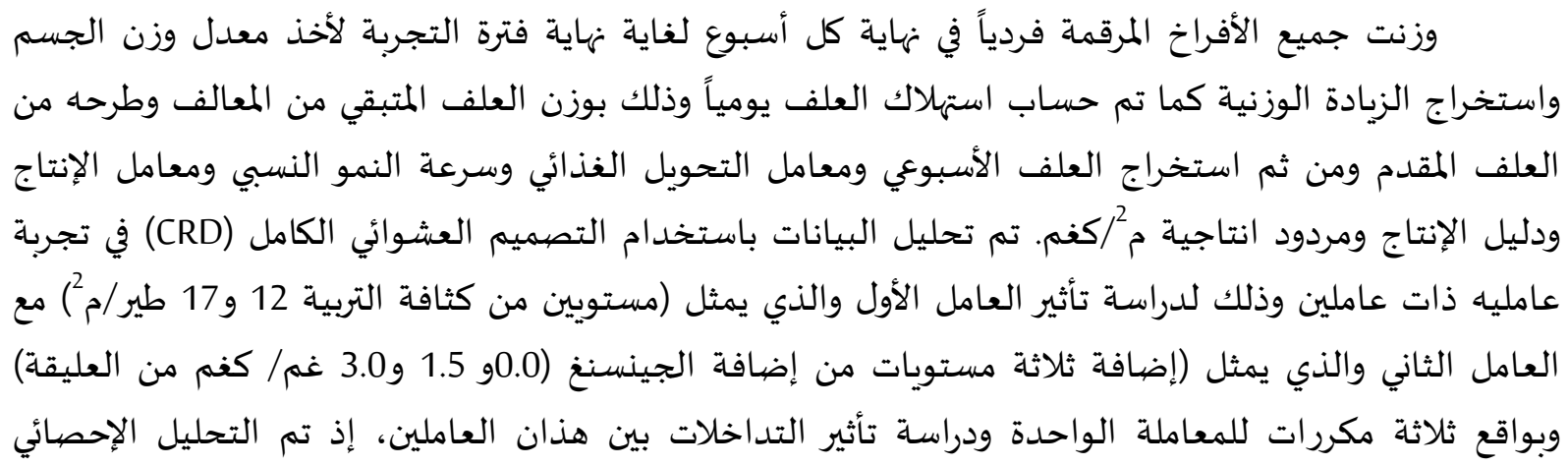 } \\
\hline
\end{tabular}


باستخدام البرنامج الجاهز (SAS، 2003) فضلاً عن اختبار معنوية الفروق بين المتوسطات المدروسة باستخدام اختبار دنكن متعدد المدى وعند مستويين من المعنوية (0.01>p). تم التحليل الإحصائي وفق الأنموذج الرياضي الآتي:

$Y i j k l=\mu+S i+E j+(S E) i j+e i j l$

إذ إن:-

E قيمة المشاهدة التي يؤثر عليها المستوى i من العامل S والمستوى ز من العامل Yijkl

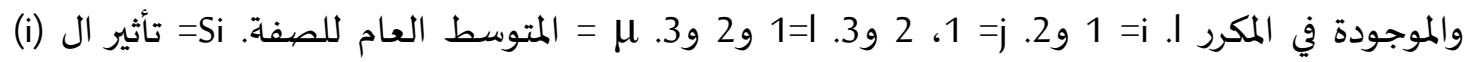
(الكثافة 12 و17 طير/م2). Ej = تأثير (j) من مستويات إضافة الجينسنغ (0 و1.5 و3.0) غم/ كغم.

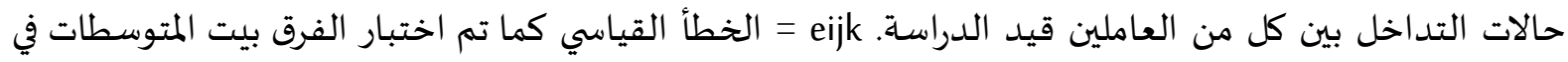
حالة وجود فروق معنوية حسب اختبار نكن للموازنة بين المتوسطات.

\section{النتائج والمناقشـة.}

يوضح الجدول (2) عدم وجود فروقات معنوية تحت مستوى احتمال (10.05) بين اختلاف كثافتي التربية

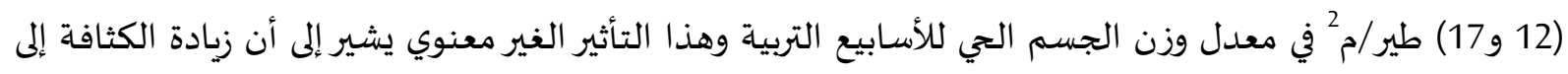

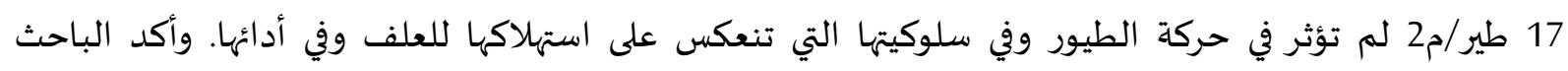

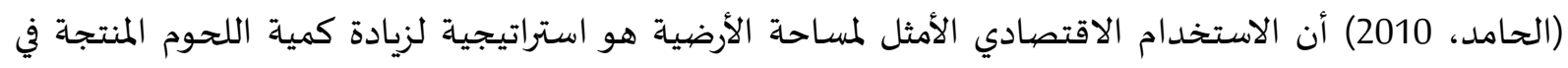

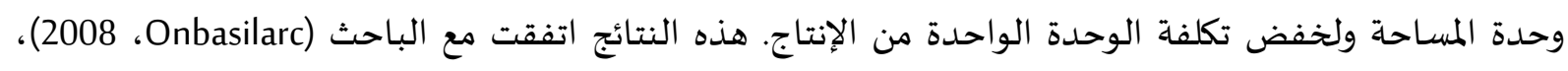
(Udebiyi)

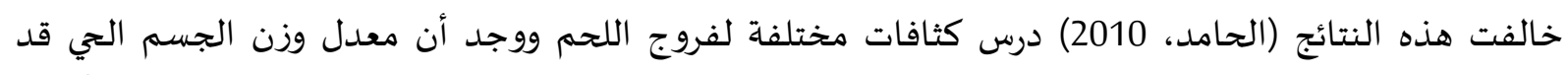

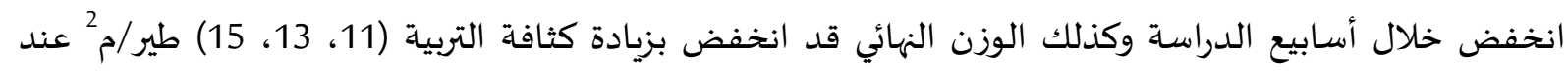

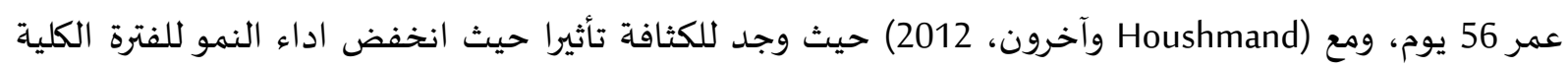

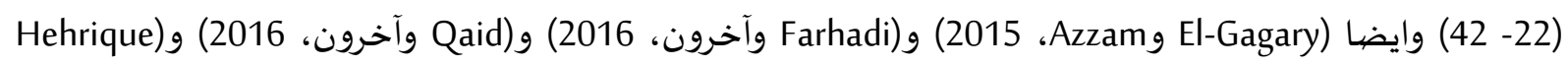

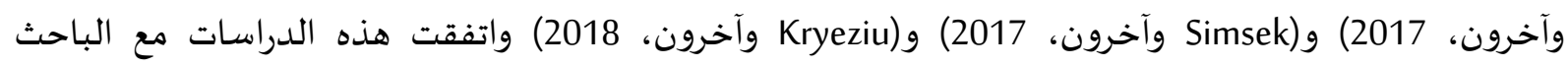
(Mandilind)

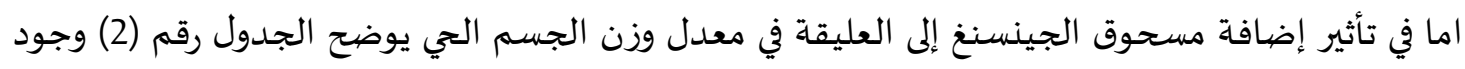
فروقات معنوية بين المستويات المختلفة للإضافة، ففي الأسبوع الثاني تفوقت الإضافة (1.5) غم على الإضافة إنيافة (3.0) غم/كغم، وفي الأسبوع الثالث نلاحظ أن الإضافة (1.5) غم تفوقت على المعاملة بدون إضافة وعلى الماتلى الإضافة (3.0)

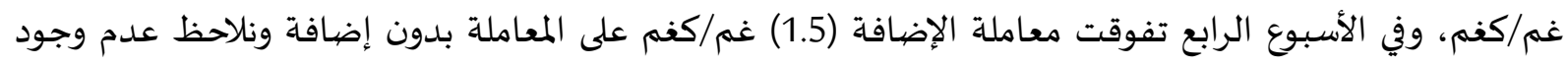

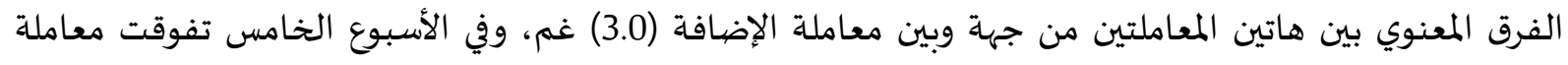

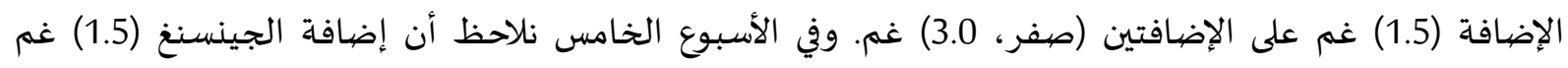

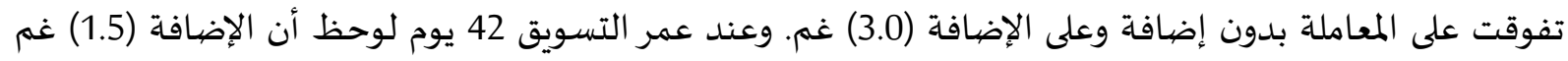

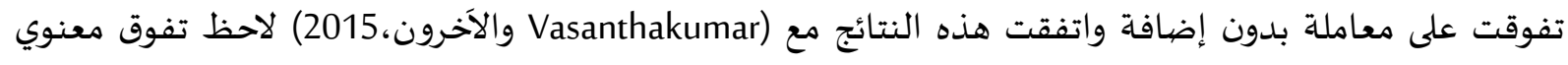
في وزن الجسم عند إضافة مسحوق جذور الجينسنغ بمقدار(1 و0.15)\% بعمر 8 أسابيع مقارنة بمعاملة السيطرة

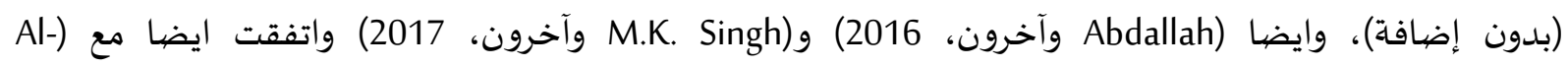
Muslimawi 
معنوياً لإضافة مسحوق جذور الجينسنغ وكذلك (ChoigChung، 2016)، وآخرون، 2017) وايضا 2018، (Chikwab) يوضح الجدول رقم (3) تأثير التداخل بين كثافة الطيور طير/م² وإضافة مسحوق الجينسنغ إلى العليقة في معدل وزن الجسم الحي الأسبوعي حيث لوحظ عدم وجود فروقات معنوية بين معاملات التداخلات المختلفة في الأسبوع الثاني، وفي الأسبوع الثالث لوحظ تفوق معنوي للمعاملة الثانية على معاملة الأولى وعلى المعاملة الرابعة

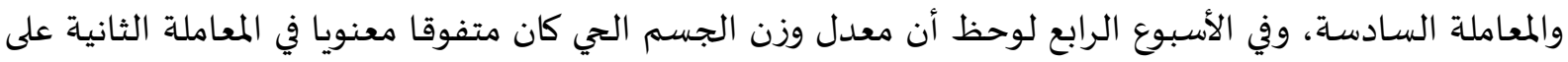
الرابعة ومع المعاملة الثالثة والمعاملة الخامسة والمعاملة السادسة، وفي الأسبوع الخامس تفوقت المعاعة المعاملة الثانية والمعاملة الخامسة على

جدول (2) تأثير كثافة الطيور طير/م2 وإضافة مسحوق الجينسنغ غم/كغم في معدل وزن الجسم الحي

\begin{tabular}{|c|c|c|c|c|c|}
\hline السأسبوع السادس & الخالسبوع & الأسبوع & الثالث الأسبوع & الأسبانيو & المعاملات الأسـابيع \\
\hline \multicolumn{6}{|c|}{ تأثير كثافة الطيور طير/م² } \\
\hline $\begin{array}{c}\mathfrak{1} 3077.14 \\
36.19 \pm\end{array}$ & $\begin{array}{l}2319.29 \\
27.92 \pm\end{array}$ & $\begin{array}{c}1417.50 \\
17.83 \pm\end{array}$ & $\begin{array}{l}\mathbf{1} 769.21 \\
16.37 \pm\end{array}$ & $\begin{array}{c}324.60 \\
4.95 \pm\end{array}$ & 12 \\
\hline $\begin{array}{c}3054.79 \\
44.98 \pm\end{array}$ & $\begin{array}{l}2287.78 \\
42.48 \pm\end{array}$ & $\begin{array}{c}1389.41 \\
26.12 \pm\end{array}$ & $\begin{array}{l}\text { أ } 728.0 \\
18.57 \pm\end{array}$ & $\begin{array}{c}330.33 \\
4.10 \pm\end{array}$ & 17 \\
\hline \multicolumn{6}{|c|}{ تأثير إضافة الجينسنغ غم/كغم عليقة } \\
\hline $\begin{array}{c}2975.24 \\
46.68 \pm\end{array}$ & $\begin{array}{c}2254.44 \\
31.40 \pm\end{array}$ & $\begin{array}{c}1359.44 \\
28.37 \pm\end{array}$ & $\begin{array}{l}713.69 \\
24.24 \pm\end{array}$ & $\begin{array}{c}331.5 \\
6.56 \pm\end{array}$ & صفر \\
\hline $\begin{array}{c}\text { أ } 3135.22 \\
56.21 \pm\end{array}$ & $\begin{array}{l}2401.72 \\
59.44 \pm\end{array}$ & $\begin{array}{c}\text { أ } 1448.31 \\
24.70 \pm\end{array}$ & $\begin{array}{c}802.62 \\
11.94 \pm\end{array}$ & $\begin{array}{c}334.60 \\
4.21 \pm\end{array}$ & 1.5 \\
\hline $\begin{array}{c}3087.83 \text { أب } 39.19 \pm \\
39.19\end{array}$ & $\begin{array}{c}2254.44 \\
24.55 \pm\end{array}$ & $\begin{array}{c}1402.6 \\
26.11 \pm\end{array}$ & $\begin{array}{l}730.33 \\
22.03 \pm\end{array}$ & $\begin{array}{c}316.47 \\
4.94 \pm\end{array}$ & 3.0 \\
\hline
\end{tabular}

الحروف المختلفة في العمود الواحد تشير إلى وجود فروقات معنوية بين المتوسطات ثـ الخطأ القياسي المعاملة الرابعة ولم تختلف هاتين المعاملتين معنويا مع المعاملة الأولى والمعاملة الثالثة ومع المعاملة السادسة، وفي الأسبوع السادس فقد تفوقت المعاملة الثانية على معاملة الأولى وايضا تفوقت على المعاملة الرابعة ولم تختلف معنويا مع الثالثة ومع الخامسة ومع السادسة وبصورة عامة نلاحظ أن المعاملة الرابعة والتي تمثلت

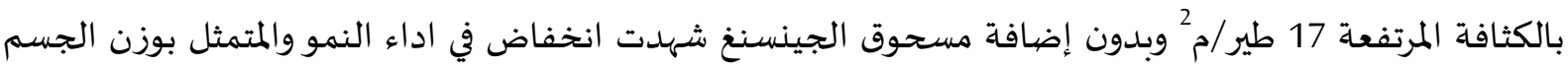

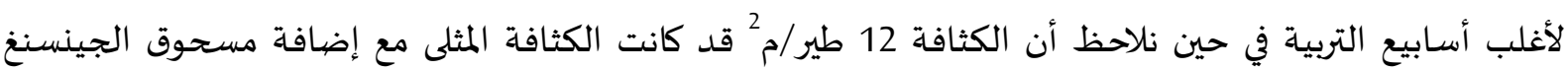

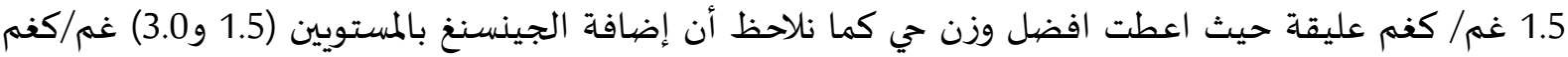

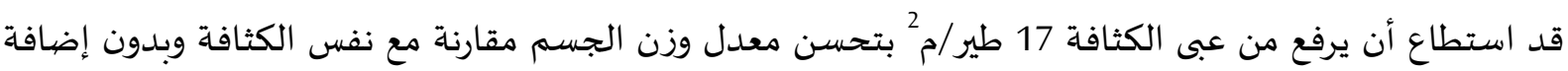

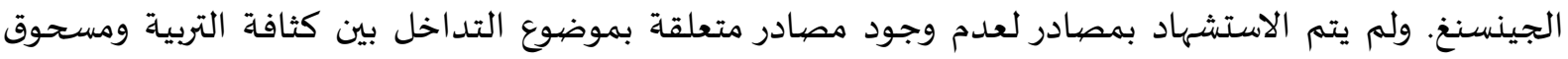




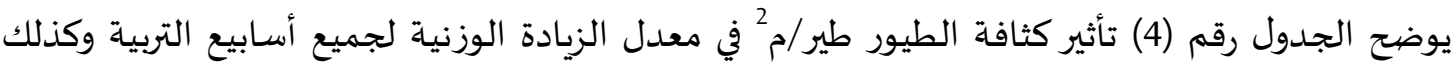

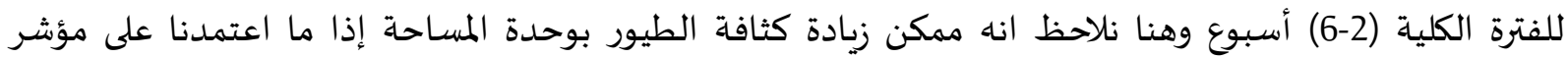
الزيادة الوزنية حيث أنها لم تتغير بتغير كثافة الطيور خلال التربية وهذا ما ينعكس على تكلفة الوحدة الواحدة من الكغم الواحد من اللحم المنتج حيث يساهم بخفض سعر الكلفة الإنتاجية. وهذه النتائج اتفقت مع هذه النتائج الباحث (Adebiyi وآخرون، 2011) ولUzum وآخرون،Wang( 2013) وآخرون، 2014) و Adeyemo وآخرون،

2016

جدول (3) تأثير التداخل بين كثافة الطيور وإضيافة مسحوق الجينسنغ إلى العليقة في معدل وزن الجسم الحي.

\begin{tabular}{|c|c|c|c|c|c|c|c|}
\hline السادس الأسبوع & الخامس & الرابع الأسبوع & الثالث الأسبوع & الأسبانيوع & غم/كغم الجينسنغ & طير الكثافة & ـ. الأسابيع \\
\hline $\begin{array}{c}2951.56 \text { ب } \\
56.99 \pm\end{array}$ & $\begin{array}{c}2300.0 \text { أ ب } 47.29 \\
4\end{array}$ & $\begin{array}{c}1346.9 \text { أ ب } 20.72 \pm \\
\text { ب }\end{array}$ & $\begin{array}{l}725.6 \\
34.73 \pm\end{array}$ & $\begin{array}{c}328.69 \\
11.23 \pm\end{array}$ & صفر & 12 & 12 المعاملة الأولى /م² صفر \\
\hline $\begin{array}{c}\text { أ } 3217.22 \\
61.88 \pm\end{array}$ & $\begin{array}{c}2403.43 \\
49.81 \pm\end{array}$ & $\begin{array}{c}469.96 \\
21.35 \pm\end{array}$ & $\begin{array}{c}820.58 \\
9.85 \pm\end{array}$ & $\begin{array}{c}334.20 \\
5.06 \pm\end{array}$ & 1.5 & 12 & 12 المعاملة الثانية /2 1.5 غمية 1.5 \\
\hline $\begin{array}{c}3063.4 \text { أ ب } 35.30 \pm \\
35.4\end{array}$ & $\begin{array}{c}2254.4 \\
37.75 \pm\end{array}$ & $\begin{array}{c}1385.7 \text { أ ب } 41.12 \pm \\
\text { ب }\end{array}$ & $\begin{array}{l}761.2 \\
27.07 \pm\end{array}$ & $\begin{array}{c}311.18 \\
7.17 \pm\end{array}$ & 3.0 & 12 & 12 المعاملة الثالثة $2.0+3.0$ \\
\hline $\begin{array}{c}2998.93 \\
76.64 \pm\end{array}$ & $\begin{array}{c}2208.89 \\
37.88 \pm\end{array}$ & $\begin{array}{c}1322.00 \\
51.40 \pm\end{array}$ & $\begin{array}{c}701.82 \\
35.44 \pm\end{array}$ & $\begin{array}{c}334.24 \\
7.42 \pm\end{array}$ & صفر & 17 & 17 المعاملة الرابعة غمية + صفر \\
\hline $\begin{array}{c}335.22 \\
88.97 \pm\end{array}$ & $\begin{array}{l}2400.00 \\
111.95 \pm\end{array}$ & 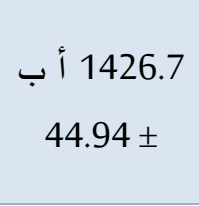 & $\begin{array}{l}784.7 \\
20.68 \pm\end{array}$ & $\begin{array}{c}335.00 \\
7.04 \pm\end{array}$ & 1.5 & 17 & 17 اطمعاملة الخامسة /م²+1.5 \\
\hline $\begin{array}{c}3112.2 \\
71.64 \pm\end{array}$ & $\begin{array}{c}2254.4 \text { أ ب } 33.71 \pm \\
\text { ب }\end{array}$ & 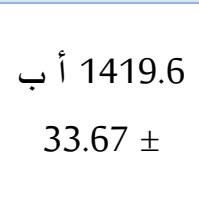 & $\begin{array}{l}694.44 \\
33.02 \pm\end{array}$ & $\begin{array}{c}321.76 \\
6.73 \pm\end{array}$ & 3.0 & 17 & 17 المعاملة السادسة/2 \\
\hline
\end{tabular}

الحروف المختلفة في العمود الواحد تشير إلى وجود فروقات معنوية بين المتوسطات د الخطأ القياسي

واختلفت (Houshmand وآخرون، 2012) ولنفس الباحث لسنة 2014 لاحظ نفس النتيجة و(Cengiz) وآخرون، 2015) و(Azzam-Gagary و، Q 2015) و وآخرون، 2016) وكذلك الباحث (Simsek وآخرون، 2017) و Hehrique وآخرون، 2017) وSun وآخرون، 2018) و(Kryeziu وآخرون، 2018) و(Mandilind وآخرون، 2018) وWenjia) وآخرون، 2019) و( اوآخرون، 2019) و(Liu وآخرون، 2020). يتضح من الجدول رقم (4) عدم وجود

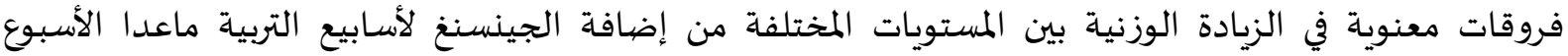
الثالث حيث تفوقت الإضافة 1.5 غم جينسنغ معنويا على المعاملة بدون إضافة في حين أن الإضافة 3 غم لم 
تختلف معنويا مع السيطرة ونلاحظ ايضا بان الزيادة الوزنية للفترة الكلية (2-6) أسبوع لم تتأثر معنويا بمستويات

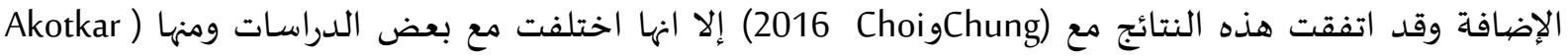
وآخرون، 2007) حيث تحسن معدل الزيادة الوزنية بإضافة مسحوق جذور الجينسنغ وكذلك (Abdallah وآخرون،

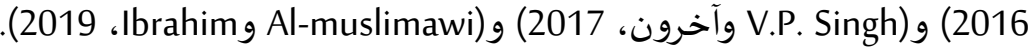
يوضح الجدول رقم (5) تأثير التداخل بين كثافة الطيور طير/م² وإضافة مسحوق الجينسنغ في معدل الزيادة الوزنية الأسبوعية والفترة الكلية (2-6) أسبوع وجود فروق معنوية بين التداخلات المختلفة في الأسبوع الثاني حيث تفوقت المعاملة الثانية معنويا على المعاملة الثالثة والسادسة في حين نجد انه لا يوجد تأثير معنوي للمعاملتين الأولى والثالثة والسادسة من التداخل مع المعاملة الثانية أما في الأسبوع الثالث فقد كانت المعاملة الثانية متفوقة معنويا مقارنة بالمعاملة الأولى والرابعة والسادسة في حين انها لم تختلف معنويا مع المعاملة الخامسة وأن هذا التأثير للتداخل لم يكن معنويا في الأسبوعين الرابع والخامس بينما في الأسبوع السادس فقد تفوقت المعاملة الثانية على

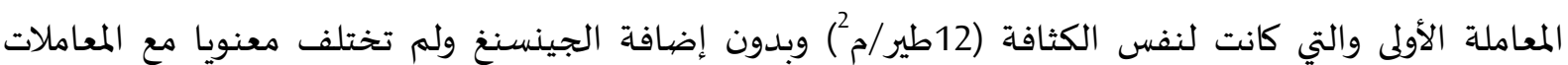
الثالثة والرابعة والخامسة والسادسة

جدول (4) تأثير كثافة الطيور وإضافة مسحوق الجينسنغ في معدل الزيادة الوزنية الأسبوعية والكلية

\begin{tabular}{|c|c|c|c|c|c|c|}
\hline الكلية الزيادة (2-6ية & السادس الأسبوع & الخامسبوع & الرابع الأسبوع & الأسبالث & الأسباني & wal \\
\hline \multicolumn{7}{|c|}{ تأثير كثافة الطيور طير/م² } \\
\hline 2867.08 أ & 857.07 & 897.05 أ & أ656.35 & 438.51 & 156.79 أ & \multirow{2}{*}{12} \\
\hline $47.43 \pm$ & $93.27 \pm$ & $29.82 \pm$ & $14.17 \pm$ & $16.31 \pm$ & $4.25 \pm$ & \\
\hline 2649.01 & 797.49 & 862.67 & 664.79 & 396.78 & 151.08 & \multirow{2}{*}{17} \\
\hline $51.08 \pm$ & $35.38 \pm$ & $25.94 \pm$ & $27.80 \pm$ & $16.09 \pm$ & $3.76 \pm$ & \\
\hline \multicolumn{7}{|c|}{ تأثير إضافة الجينسنغ غم/كغم عليقة } \\
\hline 2799.2 & 720.04 & 891.44 & 650.73 & 374.65 & 161.87 أ & \multirow{2}{*}{ صفر } \\
\hline $45.49 \pm$ & $46.49 \pm$ & $33.99 \pm$ & $35.70 \pm$ & $21.65 \pm$ & $5.69 \pm$ & \\
\hline 2805.5 & 928.1 & 907.41 & 649.12 & 464.41 & 158.61 & \multirow{2}{*}{1.5} \\
\hline $72.39 \pm$ & $36.08 \pm$ & $35.45 \pm$ & $19.50 \pm$ & $11.95 \pm$ & $4.10 \pm$ & \\
\hline 2683.2 & 833.3 & 840.72 & 681.86 & 413.88 أب & 141.32 & \multirow{2}{*}{3.0} \\
\hline $65.37 \pm$ & $32.24 \pm$ & $32.88 \pm$ & $23.29 \pm$ & $20.77 \pm$ & $3.42 \pm$ & \\
\hline
\end{tabular}

الحروف المختلفة في العمود الواحد تشير إلى وجود فروقات معنوية بين المتوسطات \pm الخطأ القياسي جدول (5) تأثير التداخل بين كثافة الطيور وإضافة الجينسنغ في معدل الزيادة الوزنية الأسبوعية والكلية.

\begin{tabular}{|c|c|c|c|c|c|c|c|c|}
\hline 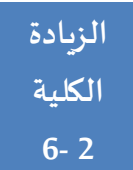 & السادس الأسبوع & الخامس الأسبوع & الرابع الأسبوع & الثالث الأسبوع & الأسباني & غم/كفم الجينسنغ & كئافة & \\
\hline $\begin{array}{r}\text { أ } 2760.2 \\
52.62 \pm\end{array}$ & $\begin{array}{c}651.06 \\
61.05 \pm\end{array}$ & $\begin{array}{r}\text { i } 903.11 \\
54.02 \pm\end{array}$ & $\begin{array}{l}\text { أ } 669.33 \\
29.47 \pm\end{array}$ & $\begin{array}{c}385.7 \\
34.31 \pm\end{array}$ & $\begin{array}{c}168.58 \\
9.10 \pm\end{array}$ & صفر & 12 & 12 المعاملة الأولى +صفر غم \\
\hline
\end{tabular}




\begin{tabular}{|c|c|c|c|c|c|c|c|c|}
\hline الزيادة 2 & السادس الأسبوع & الخامس الأسبوع & الرابع & الثالثبوع & الثاني & غم/كفم & طيثافة & الأسـابيع \\
\hline $\begin{array}{l}\text { I } 3038.6 \\
60.24 \pm\end{array}$ & $\begin{array}{r}\mathbf{1} 813.79 \\
56.11 \pm\end{array}$ & $\begin{array}{l}141.48 \\
55.16 \pm\end{array}$ & $\begin{array}{l}\mid 656.4 \\
20.19 \pm\end{array}$ & $\begin{array}{l}479.71 \\
11.99 \pm\end{array}$ & $\begin{array}{c}160.53 \\
5.08 \pm\end{array}$ & 1.5 & 12 & 12 المعاملة الثانية \\
\hline $\begin{array}{l}2804.6 \\
99.74 \pm\end{array}$ & $\begin{array}{l}808.9 \\
43.57 \pm\end{array}$ & $\begin{array}{l}846.56 \\
46.25 \pm\end{array}$ & $\begin{array}{l}\mathbf{1} 643.7 \\
25.31 \pm\end{array}$ & $\begin{array}{l}450.9 \\
26.40 \pm\end{array}$ & $\begin{array}{c}141.24 \\
4.29 \pm\end{array}$ & 3.0 & 12 & 12 المعاملة الثالثة +3.0غ \\
\hline $\begin{array}{l}2812.3 \\
76.52 \pm\end{array}$ & $\begin{array}{l}789.3 \\
65.38 \pm\end{array}$ & $\begin{array}{l}\mathbf{1} 879.78 \\
44.25 \pm\end{array}$ & $\begin{array}{l}\text { i } 632.1 \\
66.80 \pm\end{array}$ & $\begin{array}{l}363.57 \\
27.99 \pm\end{array}$ & $\begin{array}{c}155.2 \\
\text { أ ب } \\
6.60 \pm\end{array}$ & صفر & 17 & 17 المعاملة الرابعة+مهفرغم \\
\hline $\begin{array}{l}2572.4 \\
130.3 \pm\end{array}$ & $\begin{array}{l}745.0 \\
68.99 \pm\end{array}$ & $\begin{array}{l}\mid 873.33 \\
44.81 \pm\end{array}$ & $\begin{array}{l}\mathbf{1} 642.20 \\
34.50 \pm\end{array}$ & $\begin{array}{l}449.1 \\
20.12 \pm\end{array}$ & 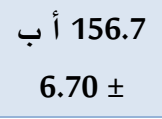 & 1.5 & 17 & 17 المعاملة الخامسة 1.5 غم غم \\
\hline $\begin{array}{l}2562.1 \\
120.4 \pm\end{array}$ & $\begin{array}{l}857.1 \\
48.67 \pm\end{array}$ & $\begin{array}{l}\text { أ } 834.89 \\
49.49 \pm\end{array}$ & $\begin{array}{l}\mid 720.04 \\
36.05 \pm\end{array}$ & $\begin{array}{l}\text { 377.7ب } \\
28.45 \pm\end{array}$ & $\begin{array}{l}141.4 \\
5.60 \pm\end{array}$ & 3.0 & 17 & 17 المعاملة السادسة مع + 3.0غم \\
\hline
\end{tabular}

الحروف المختلفة في العمود الواحد تشير إلى وجود فروقات معنوية بين المتوسطات \pm الخطأ القياسي

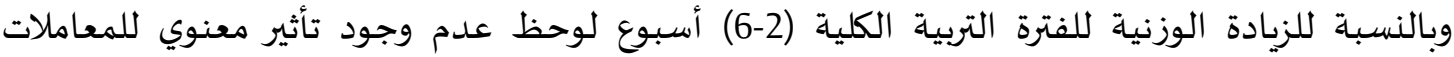
الناتجة من التداخل الناتج من تأثير الكثافتين وبوجود إضافة الجينسنغ للمعاملات قيد الدراسـة.

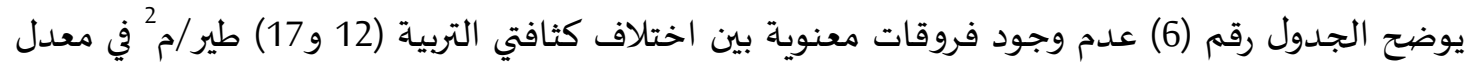

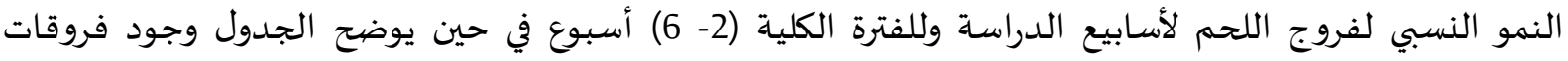
معنوية بين المستويات المختلفة من إضافة الجينسنغ إلى العليقة في معدل النمو النسبي حيث انه انخفض في

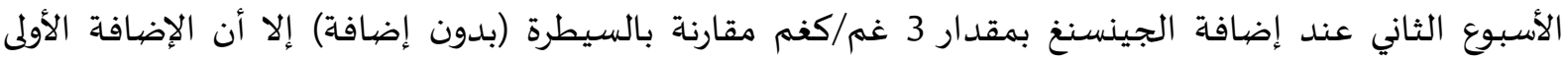

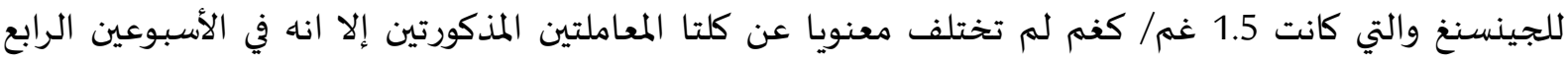

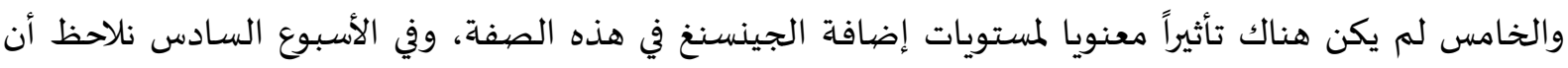

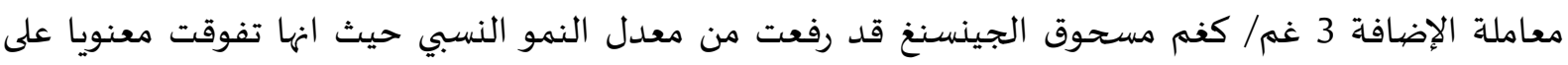
معاملة بدون الإضافة في حين أن الإضافة 1.5 غم لم تختلف معنويا مع كلا من المافياف المعاملتين السابقتين الذكر.

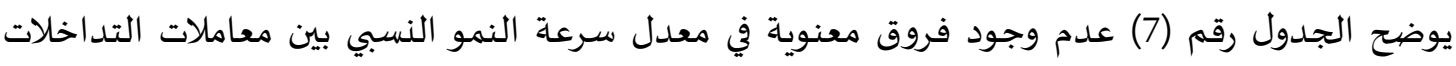

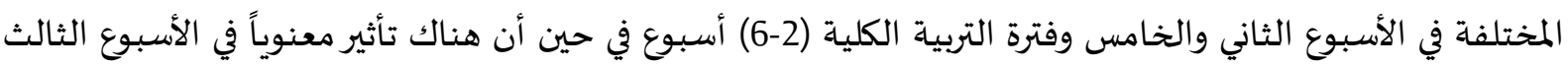

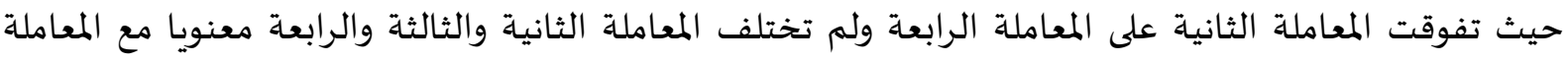

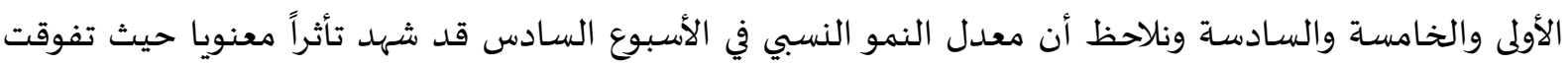

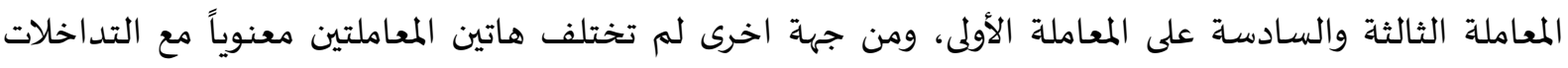
الاخرى، الثانية والرابعة والخامسـة.

يوضح الجدول رقم (8) عدم وجود فروقات معنوية في معدل استهلاك العلف بين كثافتي التربية (12 و17)

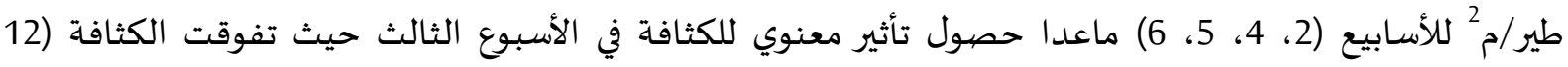

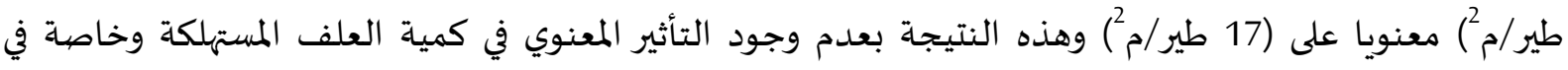

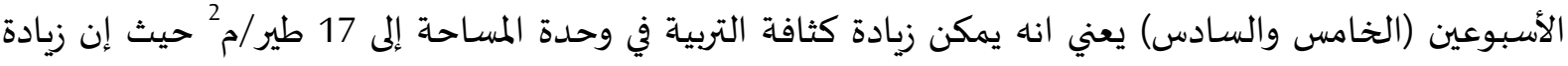

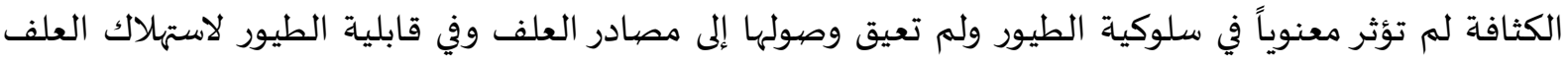

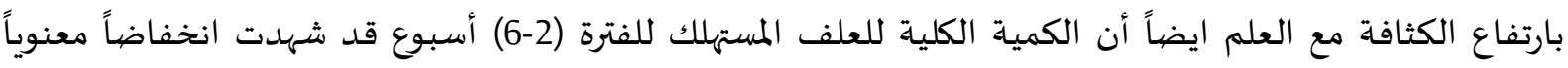
لنفس الكثافة مع الكثافة 12 طير/م2 بدون أن يتأثر وزن الجسم الجي الهائي عند عمر 42 يوم (الجدول رقم 2) 
والزيادة الوزنية للفترة الكلية (الجدول رقم4) وكذلك لم يؤثر في قابلية الطيور للتحويل الغذائي حيث إنه لم يتأثر للفترة الكلية (الجدول رقم 10) وتعتبر تكلفة العلف من بنود التكلفة الأساسي وأن خفض كمية استهلاكها تساهم في

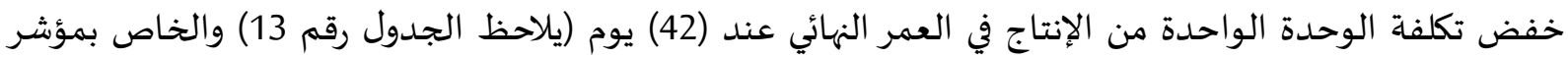

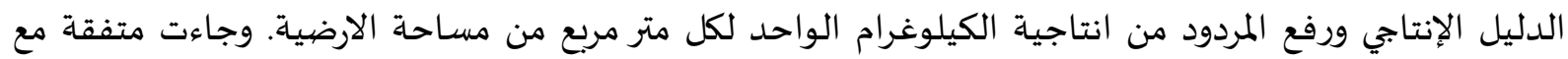

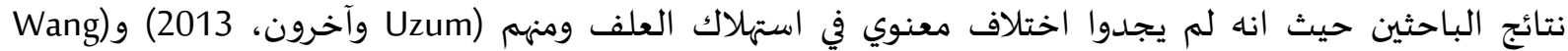
وآخرون، 2014) و(Farhadi وآخرون، 2016) و(Adeyemo وآخرون، 2016) و(Sun وآخرون، 2018) وWenjia) وآخرون، 2019). واختلفت نتائج هذه الدراسة مع نتائج بعض الدراسات ومنها(الحامد، 2010) حيث وجد أن استهلاك العلف قد انخفض خلال التربية وكذلك الكلي بزيادة كثافة (11، 13، 15) طير /م² خلال الفترة الكلية (3-

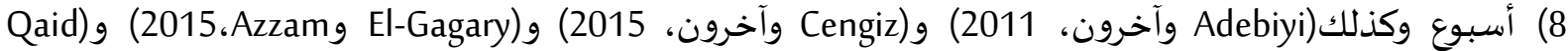

وآخرون، 2016)

جدول (6) تأثير كثافة الطيور وإضافة الجينسنغ غم/كغم في معدل النمو النسبي الأسبوعي والكلي

\begin{tabular}{|c|c|c|c|c|c|c|}
\hline النمو الكلي & السادس الأسبوع & الخامسبوع & الأسببوع & الأسبالث & الأسبانيو & / لمعاملات الأسابيع \\
\hline \multicolumn{7}{|c|}{ تأثير كثافة الطيور طير/م2 } \\
\hline 55.99 & 30.00 & 48.41 & 54.24 & 80.13 & 61.65 & \multirow{2}{*}{12} \\
\hline $1.65 \pm$ & $2.22 \pm$ & $1.64 \pm$ & $1.82 \pm$ & $2.78 \pm$ & $1.34 \pm$ & \\
\hline 55.28 & 29.58 & 46.68 & 59.72 & 75.16 & 60.77 & \multirow{2}{*}{17} \\
\hline $1.43 \pm$ & $1.77 \pm$ & $2.12 \pm$ & $2.59 \pm$ & $1.79 \pm$ & $2.21 \pm$ & \\
\hline \multicolumn{7}{|c|}{ تأثير إضافة الجينسنغ غم/كغم عليقة } \\
\hline 55.69 & 27.12 & 48.79 & 65.06 & 72.05 & أ 65.45 & \multirow{2}{*}{ صفر } \\
\hline $1.46 \pm$ & $2.48 \pm$ & $2.39 \pm$ & $3.27 \pm$ & $3.36 \pm$ & $2.39 \pm$ & \\
\hline 55.15 & 28.05 أ ب & 47.14 & 57.86 & 81.90 & 60.8 أ ب & \multirow{2}{*}{1.5} \\
\hline $1.59 \pm$ & $1.85 \pm$ & $2.00 \pm$ & $1.24 \pm$ & $1.13 \pm$ & $1.61 \pm$ & \\
\hline i 56.07 & أ & 46.71 & 63.02 & 78.98 أ ب & 57.37 & \multirow{2}{*}{3.0} \\
\hline $1.94 \pm$ & $1.98 \pm$ & $2.71 \pm$ & $3.06 \pm$ & $2.66 \pm$ & $1.09 \pm$ & \\
\hline
\end{tabular}

الحروف المختلفة في العمود الواحد تشير إلى وجود فروقات معنوية بين المتوسطات \pm الخطأ القياسي

جدول (7) تأثير كثافة الطيور وإضافة الجينسنغ غم/كغم في معدل النمو النسبي الأسبوعي والكلي (غم)

\begin{tabular}{|c|c|c|c|c|c|c|c|}
\hline السادس الأسبوع & الخامس الأسبوع & الأسببوع & الأسببوع & الأسببوع & غم/كفم الجينسنغ & طير الكثافة & المعاملات الأسابيع \\
\hline $\begin{array}{l}2951.6 \\
56.99 \pm\end{array}$ & $\begin{array}{c}2300.0 \\
47.29 \pm\end{array}$ & $\begin{array}{l}1346.9 \\
20.72 \pm\end{array}$ & $\begin{array}{l}725.6 \\
34.73 \pm\end{array}$ & $\begin{array}{l}328.7 \\
11.23 \pm\end{array}$ & صفر & 12 & 12 المعاملة الأولى /م²+ صـفر \\
\hline $\begin{array}{c}3217.22 \\
61.88 \pm\end{array}$ & 2403.43 أ & 469.96 أ & $\begin{array}{c}820.58 \\
9.85 \pm\end{array}$ & $\begin{array}{l}1334.2 \\
5.06 \pm\end{array}$ & 1.5 & 12 & 12 المعاملة الثانية /م² 1.5 \\
\hline
\end{tabular}




\begin{tabular}{|c|c|c|c|c|c|c|c|}
\hline السادس الأسبوع & الخامس الأسبوع & الأسببوع & الأسببوع & الأسانيوع & غم/كغم الجينسنغ & طير الكثافة & المعاملات الأسابيع \\
\hline $\begin{array}{l}3063.4 \\
35.30 \pm\end{array}$ & $\begin{array}{c}2254.4 \\
37.75 \pm\end{array}$ & $\begin{array}{l}\text { 1385.7 } \\
41.12 \pm\end{array}$ & $\begin{array}{l}761.2 \\
27.07 \pm\end{array}$ & $\begin{array}{l}311.18 \\
7.17 \pm\end{array}$ & 3.0 & 12 & 12 المعاملة الثالثة /2.0+3.0 \\
\hline $\begin{array}{c}2998.9 \\
76.64 \pm\end{array}$ & $\begin{array}{c}2208.89 \\
37.88 \pm\end{array}$ & $\begin{array}{c}\text { 1322.00 } \\
51.40 \pm\end{array}$ & $\begin{array}{c}701.82 \\
35.44 \pm\end{array}$ & $\begin{array}{l}334.24 \\
7.42 \pm\end{array}$ & صفر & 17 & 17 المعاملة الرابعة \\
\hline $\begin{array}{l}335.2 \\
88.97 \pm\end{array}$ & $\begin{array}{l}2400.00 \\
111.95 \pm\end{array}$ & $\begin{array}{c}1426.7 \\
44.94 \pm\end{array}$ & $\begin{array}{l}784.7 \\
20.68 \pm\end{array}$ & $\begin{array}{l}\mathbf{1} 335.0 \\
7.04 \pm\end{array}$ & 1.5 & 17 & 17 اطمير/ملة الخامسـة \\
\hline $\begin{array}{l}3112.2 \\
71.64 \pm\end{array}$ & $\begin{array}{c}2254.4 \\
33.71 \pm\end{array}$ & $\begin{array}{l}\text { 1419.6 أ ب } \\
33.67 \pm\end{array}$ & $\begin{array}{l}\text { أ } 694.44 \\
33.02 \pm\end{array}$ & $\begin{array}{l}\mathbf{1} 321.7 \\
6.73 \pm\end{array}$ & 3.0 & 17 & 17 اطمعاملة السـادسة \\
\hline
\end{tabular}

الحروف المختلفة في العمود الواحد تشير إلى وجود فروقات معنوية بين المتوسطات د الخطأ القياسي

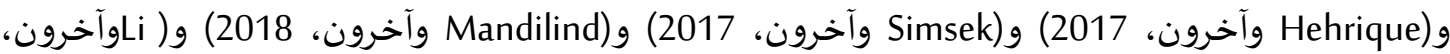

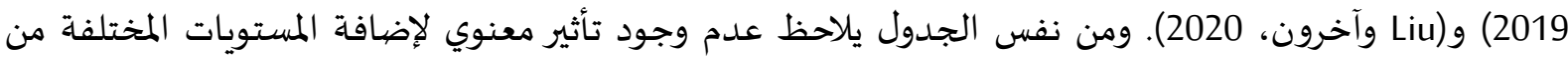
الجينسنغ (صفر، 1.5، 3.0) غم/كغم في كمية العلف المستهلكة لجميع أسابيع التربية في حين نلاحظ أن الفترة الكلية للتربية قد شهدت فروقات معنوية حيث تفوقت اضافتي الجينسنغ (1.5 و3.0) غم على المعاملة (بدون الإضافة)

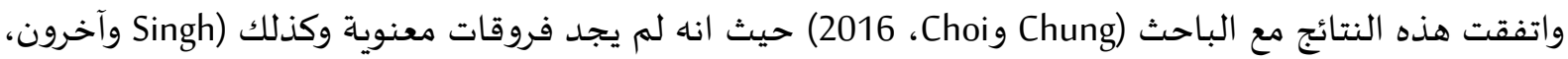

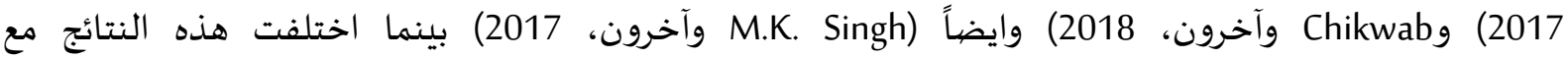
(Vآخرون، 2015) حيث وجد أن استهلاك الطيور من العلف يزداد معنويا عند إضافة (0.1 و0.15) \% من مسحوق جذور وايضاً مع (Abdallah وآخرون، 2016) (2015) يوضح الجدول رقم (9) تأثير التداخل بين كثافتي الطيور وإضافة مستويات الجينسنغ المختلفة في كمية العلف المستهلكة وكمية العلف للفترة الكلية (2-6) أسبوع وجود فروقات معنوية في الأسبوع الثاني حيث تفوقت المعاملة الأولى والثانية معنويا على المعاملتين الخامسة والسادسة وهذه المعاملات لم تختلف معنويا من جهة اخرى

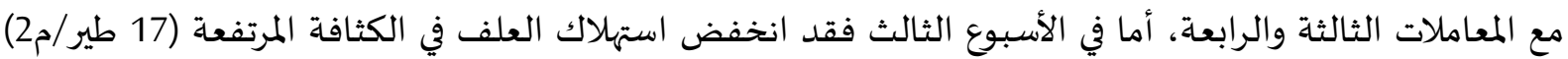

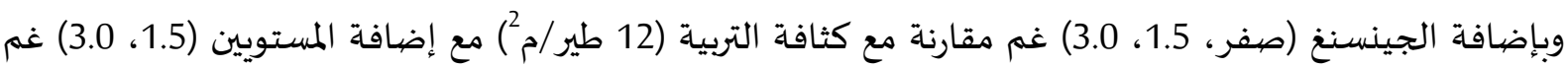

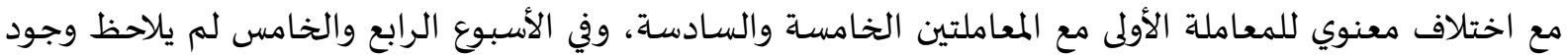
اختلاف معنوي بين التداخلات المختلفة للمعاملات، وفي الأسبوع السادس تفاوت استهلاك العلف في تداخلات التجربة حيث نلاحظ انه انخفض معنويا في المعاملة الخامسة مقارنة مع التداخلات الاخرى (الثانية والثالثة والرابعة

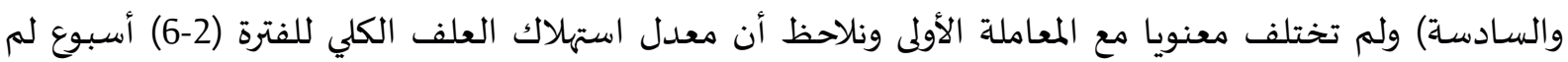

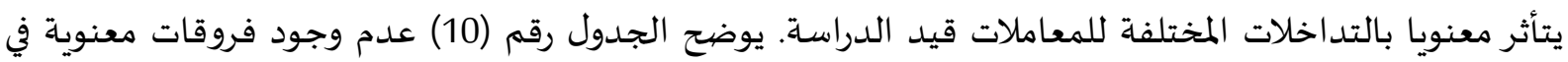

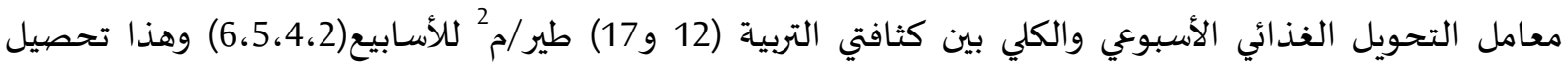

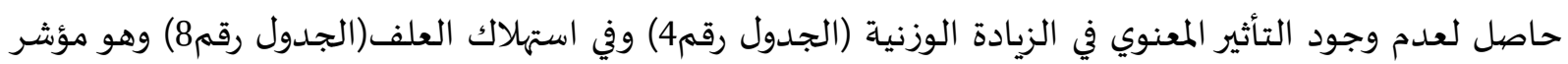


إنتاجي جيد لإمكانية رفع الكثافة بدون التأثير في اداء الطيور واتفقت مع (الحامد، 2010) حيث وجد أن معامل التحويل الغذائي لم يتأثر معنويا بكثافة التربية (11، 13، 15) طير/مّم وايضاً (Houshmand وآخرون، 2012) و Uzum وآخرون، 2013) و(Cengiz وآخرون، 2015) و(Adeyemo وآخرون، 2016) و( Farhadi وآخرون، 2016)

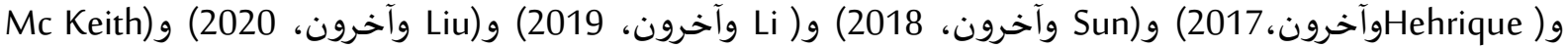
وآخرون، 2020) بينما اختلفت هذه النتائج مع (Adebiyi وآخرون، 2011) حيث اشار إلى تحسن في معامل التحويل

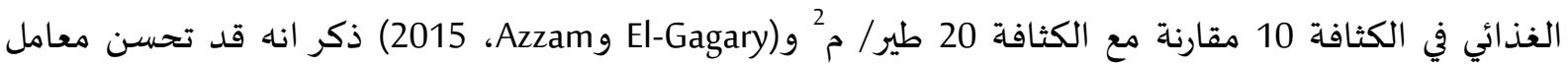
التحويل فانخفض معنويا بزيادة كثافة التربية و(Cengiz وآخرون، 2015) وQQaid وآخرون، 2016) و(Mandilind وآخرون، 2018). ومن نفس الجدول رقم (10) تبين عدم وجود فروقات معنوية بين مستويات إضافة الجينسنغ (صفر، 1.5، 3.0) غم/كغم لأسابيع التربية (2، 3، 4، 5) أسبوع ماعدا وجود تحسن في معامل التحويل في الأسبوع السادس لإضافة الجينسنغ (1.5 و3.0) غم/كغم مقارنة بمعاملة بدون إضافة الجينسنغ وقد يعود هذا إلى وجود

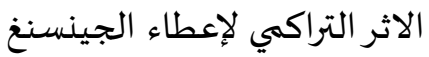

جدول (8) تأثير كثافة الطيور وإضيافة مسحوق الجينسنغ في معدل استهلاك العلف الأسبوعي والكلي

\begin{tabular}{|c|c|c|c|c|c|c|}
\hline العلف الكلي & السادس الأسبوع & الخامس الأسبوع & الأسببوع & الأسببوع & الأسببوع & المعاملات الأسابيع \\
\hline \multicolumn{7}{|c|}{ تأثير كثافة الطيور طير/م² } \\
\hline 4429.7 & 1358.9 & 1349.2 & 866.21 & 652.85 & 202.40 & \multirow{2}{*}{12} \\
\hline $66.54 \pm$ & $06.99 \pm$ & $55.94 \pm$ & $27.03 \pm$ & $8.12 \pm$ & $10.98 \pm$ & \\
\hline 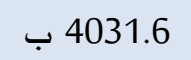 & 1249.8 & 1258.2 & أ 832.73 & 515.9ب & 191.87 & \multirow{2}{*}{17} \\
\hline $182.57 \pm$ & $16.23 \pm$ & $121.37 \pm$ & $86.35 \pm$ & $17.26 \pm$ & $7.36 \pm$ & \\
\hline \multicolumn{7}{|c|}{ تأثير إضافة الجينسنغ غم/كغم عليقة } \\
\hline 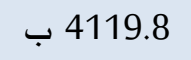 & 1260.7 & 1265.6 & 871.98 & 513.27 & 208.29 & \multirow{2}{*}{ صفر } \\
\hline $103.35 \pm$ & $46.04 \pm$ & $47.12 \pm$ & $59.04 \pm$ & $37.19 \pm$ & $13.51 \pm$ & \\
\hline 4561.27 & 1494.3 & 1372.3 & 845.79 & 613.02 & 235.90 & \multirow{2}{*}{1.5} \\
\hline $171.05 \pm$ & $193.63 \pm$ & $49.67 \pm$ & $21.03 \pm$ & $41.28 \pm$ & $11.78 \pm$ & \\
\hline 4298.02 & 1341.1 & 1261.1 & 968.24 & 554.60 & 173.82 & \multirow{2}{*}{3.0} \\
\hline $129.99 \pm$ & $23.75 \pm$ & $115.6 \pm$ & $122.8 \pm$ & $33.53 \pm$ & $9.36 \pm$ & \\
\hline
\end{tabular}

الحروف المختلفة في العمود الواحد تشير إلى وجود فروقات معنوية بين المتوسطات \pm الخطأ القياسي جدول (9) تأثير التداخل بين كثافة الطيور وإضافة مسحوق الجينسنغ في كمية العلف المستهلكة الأسبوعية الكلية

\begin{tabular}{|c|c|c|c|c|c|c|c|c|}
\hline الكلي 2-6 العلف & السادس الأسبوع & الخامس الأسبوع & الرابع الأسبوع & ال الثالث & الألثبون & غمث/كفم & كثافة & \\
\hline $\begin{array}{l}\text { I } 4203.4 \\
133.90 \pm\end{array}$ & $\begin{array}{l}1218 \text { أ ب } 289.4 \pm \\
289.4\end{array}$ & $\begin{array}{l}\text { أ } 1297.7 \\
128.40 \pm\end{array}$ & $\begin{array}{l}929.0 \\
58.35 \pm\end{array}$ & $\begin{array}{l}540.1 \\
16.63 \pm\end{array}$ & $\begin{array}{l}\text { I } 222.74 \\
22.64 \pm\end{array}$ & صفر & 12 & 12 المعاملة الأولى مُصفرغم \\
\hline $\begin{array}{l}4571.7 \\
54.02 \pm\end{array}$ & $\begin{array}{l}1310.2 \\
85.57 \pm\end{array}$ & $\begin{array}{l}1341.8 \\
56.40 \pm\end{array}$ & $\begin{array}{l}\mathbf{1} 852.4 \\
25.20 \pm\end{array}$ & $\begin{array}{r}\mathbf{6} 666.78 \\
51.68 \pm\end{array}$ & $\begin{array}{l}\mathbf{2} 213.50 \\
18.03 \pm\end{array}$ & 1.5 & 12 & 12 المعاملة الثانية مُ2+1.5غم \\
\hline
\end{tabular}




\begin{tabular}{|c|c|c|c|c|c|c|c|c|}
\hline الكلف 2-6 العلف & السادس الأسبوع & الخامس الأسبوع & الأسبع & الثالثبوع & الألثانيوع & غم/كفم & كثئة & الأسـابيع \\
\hline $\begin{array}{l}\text { i } 4353.5 \\
151.65 \pm\end{array}$ & $\begin{array}{l}1358.9 \\
32.22 \pm\end{array}$ & $\begin{array}{l}\text { I } 1303.7 \\
121.65 \pm\end{array}$ & $\begin{array}{l}\mathbf{8} 887.34 \\
37.83 \pm\end{array}$ & $\begin{array}{l}\mid 616.47 \\
23.79 \pm\end{array}$ & $\begin{array}{l}187.0 \\
16.44 \pm\end{array}$ & 3.0 & 12 & 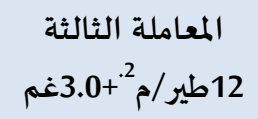 \\
\hline $\begin{array}{l}\text { I } 4475.8 \\
141.83 \pm\end{array}$ & $\begin{array}{l}1444.4 \\
59.96 \pm\end{array}$ & $\begin{array}{c}1425.24 \\
67.57 \pm\end{array}$ & $\begin{array}{l}910.2 \\
42.01 \pm\end{array}$ & $\begin{array}{l}502.1 \\
51.02 \pm\end{array}$ & $\begin{array}{l}194 \text { أ ب } 13.81 \pm \\
13.81\end{array}$ & صفر & 17 & 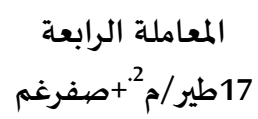 \\
\hline $\begin{array}{l}\mid 4100.1 \\
90.11 \pm\end{array}$ & $\begin{array}{l}\text { 1185.3 } \\
275.0 \pm\end{array}$ & $\begin{array}{c}1318.72 \\
17.85 \pm\end{array}$ & $\begin{array}{l}\mathbf{1} 811.4 \\
33.98 \pm\end{array}$ & $\begin{array}{l}606.3 \\
15.86 \pm\end{array}$ & $\begin{array}{l}178.6 \\
17.04 \pm\end{array}$ & 1.5 & 17 & 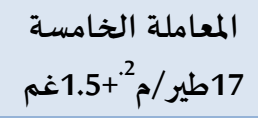 \\
\hline $\begin{array}{l}\text { I } 4326.1 \\
105.93 \pm\end{array}$ & $\begin{array}{l}1415.4 \\
38.51 \pm\end{array}$ & $\begin{array}{c}\text { أ } 1243.99 \\
85.84 \pm\end{array}$ & $\begin{array}{l}976.3 \\
43.89 \pm\end{array}$ & $\begin{array}{l}528.3 \\
23.34 \pm\end{array}$ & $\begin{array}{l}162.2 \\
3.36 \pm\end{array}$ & 3.0 & 17 & 17 المعاملة السـادسة م-+3.0غم \\
\hline
\end{tabular}

الحروف المختلفة في العمود الواحد تشير إلى وجود فروقات معنوية بين المتوسطات د الخطأ القياسي

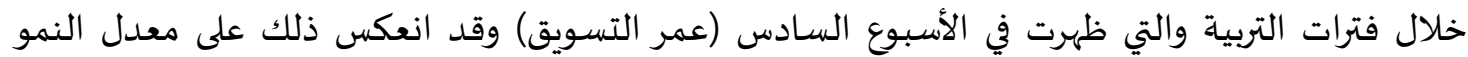

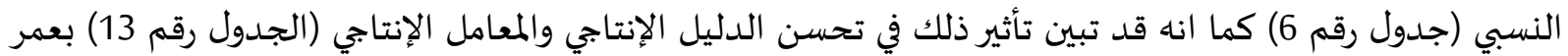

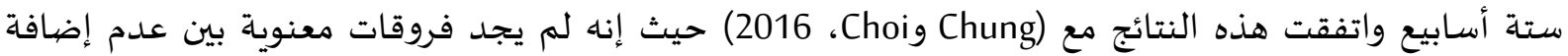

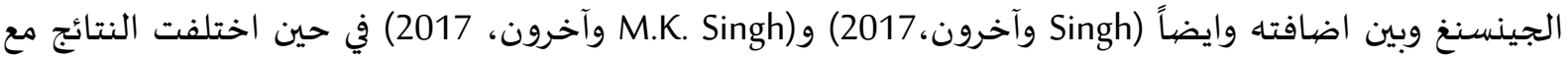
(Vasanthakumar) جدول(10) تأثير كثافة الطيور وإضافة الجينسنغ غم/كفم في معامل التحويل الغذائي الأسبوعي الكلي

\begin{tabular}{|c|c|c|c|c|c|c|}
\hline معامل التحويل & السادس الأسبوع & الخامس الأسبوع & الأسببع & الأسبوع الثالث & الأسببع & المعاملات الأسابيع \\
\hline \multicolumn{7}{|c|}{ تأثير كثافة الطيور طير/م² } \\
\hline 1.54 & 1.59 أ & 1.50 & $\uparrow 1.32$ & 1.49 & 1.29 أ & \multirow{2}{*}{12} \\
\hline $0.11 \pm$ & $0.04 \pm$ & $0.04 \pm$ & $0.05 \pm$ & $0.10 \pm$ & $0.03 \pm$ & \\
\hline 1.53 & 1.57 أ & 1.45 أ & 1.25 & 1.30 & 1.27 & \multirow{2}{*}{17} \\
\hline $0.09 \pm$ & $0.04 \pm$ & $0.13 \pm$ & $0.06 \pm$ & $0.08 \pm$ & $0.03 \pm$ & \\
\hline \multicolumn{7}{|c|}{ تأثير إضافة الجينسنغ غم/كغم عليقة } \\
\hline 1.48 أ & 1.75 & 1.42 & $i 1.37$ & 1.37 & 1.29 أ & \multirow{2}{*}{ صفر } \\
\hline $0.12 \pm$ & $0.08 \pm$ & $0.08 \pm$ & $0.07 \pm$ & $0.14 \pm$ & $0.04 \pm$ & \\
\hline 1.63 & 1.61 ب & 1.52 & 1.38 & 1.32 & 1.22 & \multirow{2}{*}{1.5} \\
\hline $0.12 \pm$ & $0.04 \pm$ & $0.16 \pm$ & $0.04 \pm$ & $0.07 \pm$ & $0.05 \pm$ & \\
\hline 1.60 & 1.62 & 1.50 & 1.42 & 1.34 & 1.23 & \multirow{2}{*}{3.0} \\
\hline $0.11 \pm$ & $0.06 \pm$ & $0.09 \pm$ & $0.07 \pm$ & $0.07 \pm$ & $0.06 \pm$ & \\
\hline
\end{tabular}

الحروف المختلفة في العمود الواحد تشير إلى وجود فروقات معنوية بين المتوسطات 土ـ الخطأ القياسي يوضيح الجدول رقم (11) عدم وجود فروقات معنوية في معامل التحويل الغذائي الأسبوعي بين التداخلات المختلفة للأسابيع (2، 4، 5) أما في الأسبوع الثالث فقد تحسن في المعاملة الخامسة حيث انخفض معنوديا مقارنة

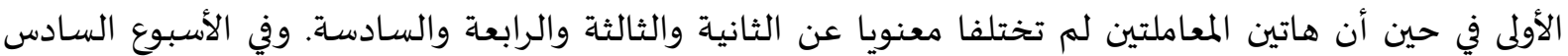
نلاحظ انخفاضه معنويا في السادسة مقارنة مع الأولى في حين أن هاتين المعاملتين لم تختلفا معنويا عن التداخلات 
الاخرى الثانية والثالثة والرابعة والخامسة وهذا تبين تأثيره في معدل النمو النسبي الجدول رقم (6). ونلاحظ ايضا أن

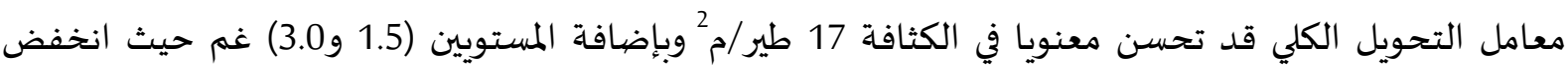

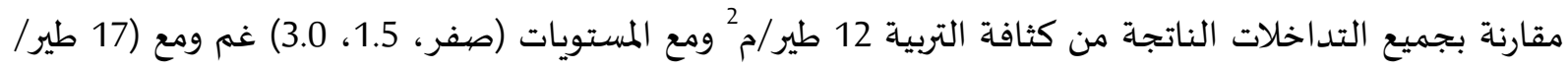

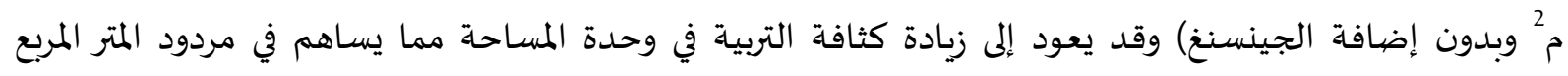

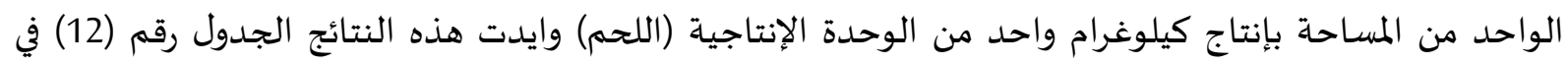

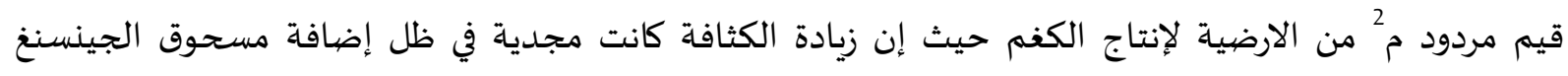

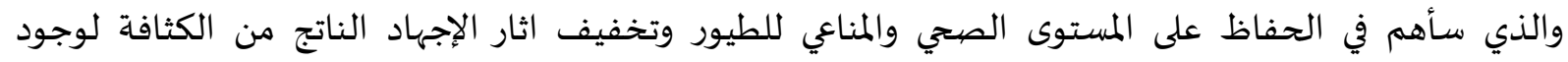

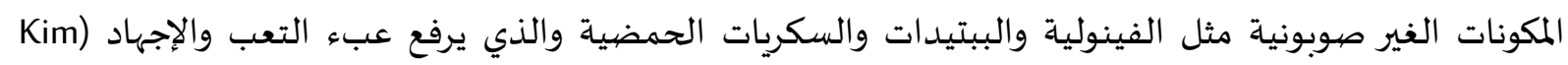

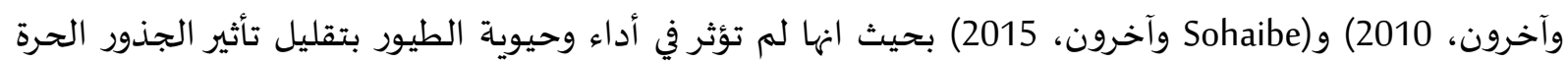

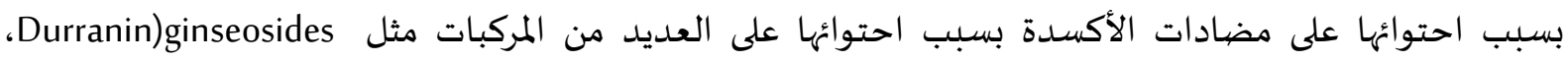

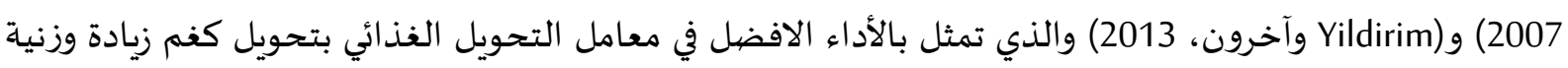
إلى كغم من العلف حيث انه يحسن نشاط انزيم الهضم فيدعم صححة الامعاء وتحسين وظائف الجهاز الهضيمي

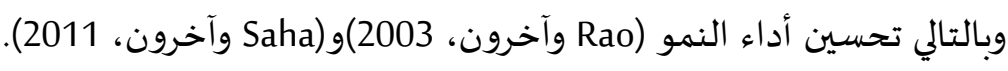
جدول (11) تأثير التداخل بين كثافة الطيور وإضافة مسحوق الجينسنغ في معامل التحويل الغذائي الأسبوعي والكلي

\begin{tabular}{|c|c|c|c|c|c|c|c|c|}
\hline الكلي 2- & السادس الأسبوع & الخامسبوع الأسبو & الرابع الأسبوع & الأسبوع & الأسبوع & غم/كغم الجينسنغ & كثير كثافة & المعاملات الأسابيع \\
\hline $\begin{array}{l}1.61 \\
0.05 \pm\end{array}$ & $\begin{array}{l}2.13 \\
0.6 \pm\end{array}$ & $\begin{array}{l}1.51 \\
0.08 \pm\end{array}$ & $\begin{array}{l}1.44 \\
0.1 \pm\end{array}$ & $\begin{array}{l}1.69 \\
0.22 \pm\end{array}$ & $\begin{array}{l}1.34 \\
0.08 \pm\end{array}$ & صفر & 12 & 12 المير/ماملة الأولى \\
\hline $\begin{array}{l}1.49 \\
0.04 \pm\end{array}$ & $\begin{array}{l}1.87 \\
0.16 \pm\end{array}$ & $\begin{array}{l}1.43 \\
0.04 \pm\end{array}$ & $\begin{array}{l}1.30 \\
0.05 \pm\end{array}$ & $\begin{array}{l}1.39 \\
0.12 \pm\end{array}$ & $\begin{array}{l}1.34 \\
0.06 \pm\end{array}$ & 1.5 & 12 & 12 المعاملة الثانية 1.5 غم \\
\hline $\begin{array}{l}1.51 \\
0.04 \pm\end{array}$ & $\begin{array}{l}1.68 \\
0.16 \pm\end{array}$ & $\begin{array}{l}1.54 \\
0.06 \pm\end{array}$ & $\begin{array}{l}1.38 \\
0.09 \pm\end{array}$ & $\begin{array}{l}1.40 \\
0.14 \pm\end{array}$ & $\begin{array}{l}1.32 \\
0.06 \pm\end{array}$ & 3.0 & 12 & 12 المعاملة الثالثة.+3.0 غم \\
\hline $\begin{array}{l}1.48 \\
0.04 \pm\end{array}$ & $\begin{array}{l}1.83 \\
0.16 \pm\end{array}$ & $\begin{array}{l}11.34 \\
0.14 \pm\end{array}$ & $\begin{array}{l}1.34 \\
0.12 \pm\end{array}$ & $\begin{array}{l}1.44 \\
0.19 \pm\end{array}$ & $\begin{array}{l}1.24 \\
0.05 \pm\end{array}$ & صفر & 12 & 17 المعاملة الرابعة /م2.+صفرغم \\
\hline $\begin{array}{l}1.33 \\
0.04 \pm\end{array}$ & $\begin{array}{l}1.59 \\
0.16 \pm\end{array}$ & $\begin{array}{l}i .51 \\
0.29 \pm\end{array}$ & $\begin{array}{l}1.27 \\
0.08 \pm\end{array}$ & $\begin{array}{l}1.15 \\
0.04 \pm\end{array}$ & $\begin{array}{l}1.14 \\
0.03 \pm\end{array}$ & 1.5 & 17 & 17 المعاملة /م1.21.5 غم \\
\hline $\begin{array}{l}1.33 \\
0.07 \pm\end{array}$ & $\begin{array}{l}1.55 \\
0.17 \pm\end{array}$ & $\begin{array}{l}1.49 \\
0.19 \pm\end{array}$ & $\begin{array}{l}1.19 \\
0.09 \pm\end{array}$ & $\begin{array}{l}1.40 \\
0.09 \pm\end{array}$ & $\begin{array}{l}1.15 \\
0.08 \pm\end{array}$ & 3.0 & 17 & 17 المعاملة السادسة /23.0 غم \\
\hline
\end{tabular}

الحروف المختلفة في العمود الواحد تشير إلى وجود فروقات معنوية بين المتوسطات \pm الخطأ القياسي يوضح الجدول رقم (12) نلاحظ عدم وجود فروقات معنوية في الأسبوع الخامس لكل من مؤشر الدليل

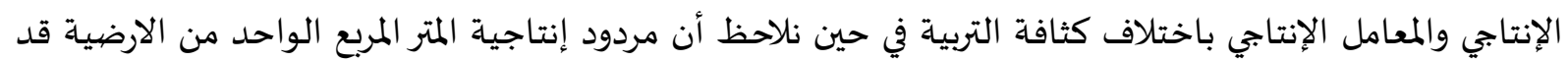

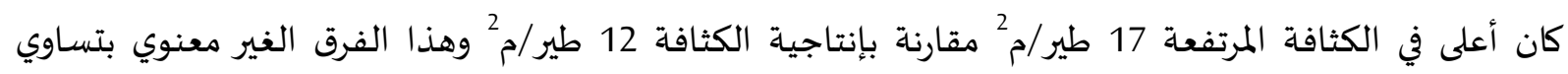

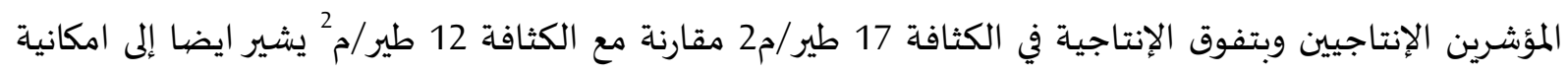

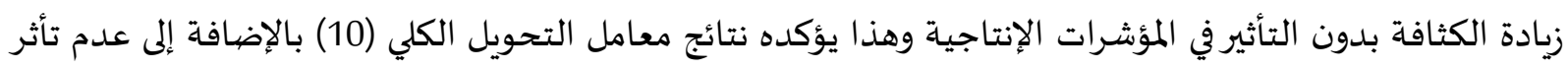


الزيادة الوزنية (3) ولنفس عمر الطيور واتفقت النتائج الباحث ( Moreiraوآخرون، 2004) حيث ذكر أن قيمة الإنتاجية للكغم/م2 تزداد بزيادة اعداد فروج اللحم في وحدة المساحة وخالفت هذه النتيجة (الحامد، 2010) وFarhadi وآخرون، 2016) و(Hehrique وآخرون، 2017) ويوضح الجدول رقم عدم وجود تأثير معنوي لاختلاف مستويات إضافة الجينسنغ في المؤشرات الإنتاجية السابقة الذكر في الأسبوع الخامس وخالفت هذه الخدات النتائج VVasanthakumar ) الاقتصادية حيث ارتفعت بمعاملة السيطرة للفترة الهائية للتربية (42) يوم. وكان مردود الإنتاجية غير معنوي وتماشت مع النتائج المستحصلة في (الجدول رقم 2) للزيادة الوزنية واختلفت هذه النتائج مع ( Vasanthakumar وآخرون، 2015). يوضح الجدول رقم (13) عدم وجود فروقات معنوية في التداخلات المختلفة للمعاملة الأولى

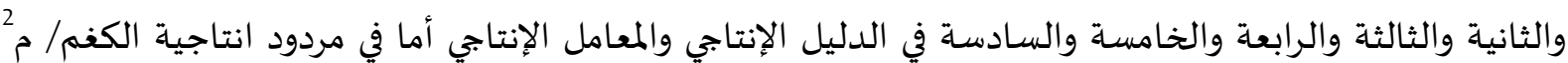
من مساحة الارضية في الأسبوع الخامس نلاحظ انه ارتفع معنويا في جميع التداخلات الناتجة من إضافة الجينسنغ

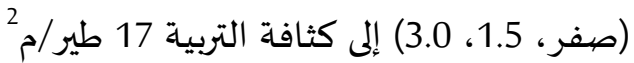

جدول (12) تأثير كثافة الطيور وإضافة الجينسنغ في المؤشرات الاقتصهادية عند الأسبوع الخامس.

\begin{tabular}{|c|c|c|c|}
\hline الإنتاجية كفم/م & المعامل الإنتاجي & الدليل الإنتاجي & \multirow{2}{*}{ المأسابيع } \\
\hline \multicolumn{3}{|c|}{ 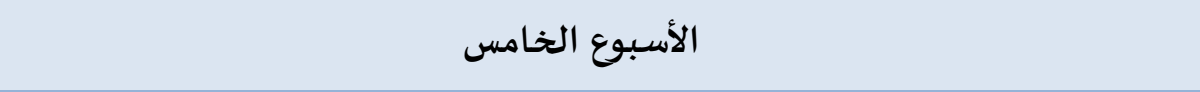 } & \\
\hline \multicolumn{4}{|c|}{ تأثير كثافة الطيور طير/م² } \\
\hline 37.21 × 0.46 ب & $4.73 \pm 58.6$ & أ $25.27 \pm 432.88$ & 12 \\
\hline $1.01 \pm 45.57$ & 55.71 & أ $28.30 \pm 419.22$ & 17 \\
\hline \multicolumn{4}{|c|}{ تأثير إضافة الجينسنغ غم/كغم عليقة } \\
\hline $2.09 \pm 40.04$ & $4.73 \pm 58.38$ & $31.52 \pm 421.85$ & صفر \\
\hline $1 \pm 1.9342 .20$ & $7.0 \pm 57.80$ & أ 433.06 أ & 1.5 \\
\hline $2.19 \pm 41.94$ & $6.08 \pm 54.71$ & أ $34.01 \pm 416.53$ & 3.0 \\
\hline
\end{tabular}

الحروف المختلفة في العمود الواحد تشير إلى وجود فروقات معنوية بين المتوسطات د الخطأ القياسي

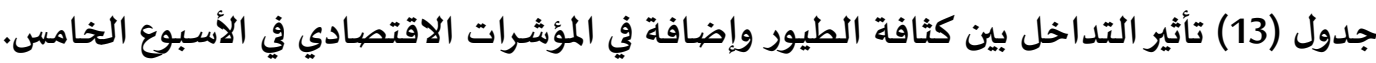

\begin{tabular}{|c|c|c|c|c|c|}
\hline الإنتاجيةكغم/2 & الأسبوع الخامل الإنتاجي & الدليل الإنتاجي & غم/كغم الجينسنغ & طير/مة & الأسعابيع \\
\hline $\begin{array}{l}28.18 \\
1.43 \pm\end{array}$ & $\begin{array}{l}58.95 \\
7.65 \pm\end{array}$ & $\begin{array}{l}\text { أ } 428.9 \\
25.51 \pm\end{array}$ & صفر & 12 & 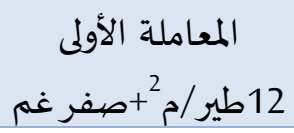 \\
\hline $\begin{array}{l}29.3 \\
2.52 \pm\end{array}$ & $\begin{array}{l}\mathbf{1} 65.84 \\
3.68 \pm\end{array}$ & $\begin{array}{c}480.02 \\
15.88 \pm\end{array}$ & 1.5 & 12 & 12 المعاملة الثانية \\
\hline $\begin{array}{c}27.38 \\
1.72 \pm\end{array}$ & $\begin{array}{l}54.97 \\
4.64 \pm\end{array}$ & $\begin{array}{c}418.26 \\
15.7 \pm\end{array}$ & 3.0 & 12 & 12 المعاملة الثالثة \\
\hline $\begin{array}{l}33.14 \\
3.19 \pm\end{array}$ & $\begin{array}{l}50.00 \\
3.12 \pm\end{array}$ & $\begin{array}{c}358.40 \\
10.1 \pm\end{array}$ & صفر & 71 & 17 المعاملة الرابعة +.برفرغم \\
\hline
\end{tabular}




\begin{tabular}{|c|c|c|c|c|c|}
\hline الإنتاجيةكغم/م 2 & الأسبوع الخامل الإنتاجي & الدليل الإنتاجي & غم/كغم الجينسنغ & طير كثافة & الأسـابيع \\
\hline $\begin{array}{l}36.01 \\
2.09 \pm\end{array}$ & $\begin{array}{c}54.16 \\
11.5 \pm\end{array}$ & $\begin{array}{c}422.33 \\
14.5 \pm\end{array}$ & 1.5 & 17 & 17طير /معاملة الخامسـة \\
\hline $\begin{array}{l}33.81 \\
1.55 \pm\end{array}$ & $\begin{array}{l}\text { I } 35.37 \\
12.28 \pm\end{array}$ & $\begin{array}{l}\text { أ } 402.0 \\
22.3 \pm\end{array}$ & 3.0 & 17 & 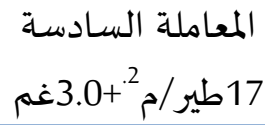 \\
\hline
\end{tabular}

الحروف المختلفة في العمود الواحد تشير إلى وجود فروقات معنوية بين المتوسطات د الخطأ القياسي.

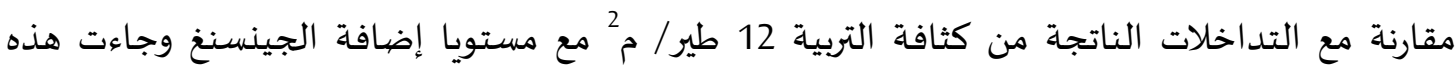
النتائج متماشية مع (الجدول رقم 3) والخاص بالزيادة الوزنية ومع (الجدول رقم 10) والخاص بمعامل معامل التحويل

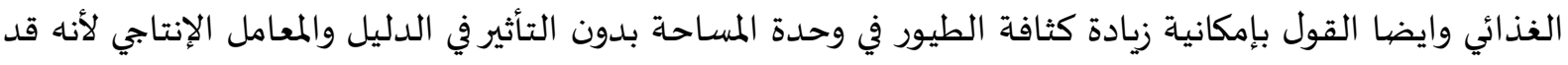

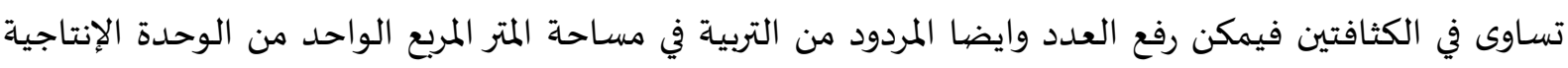

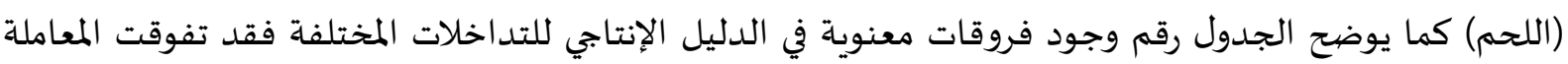

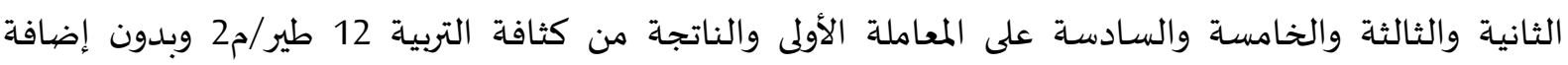

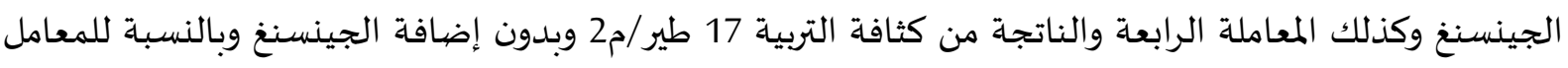

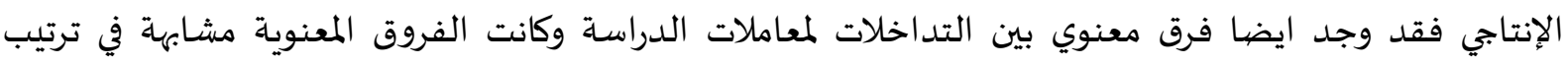
المعنوية للدليل الإنتاجي.

\section{قائمة المراجع.}

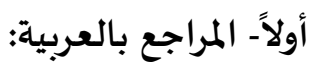

- الجلبي، عمار ماجد بشير (2019) تأثير المعاملة بزهرة البابونج وورق البلوط والمعزز الحيوي في الأداء الفسلجي

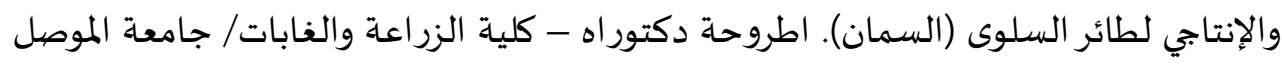

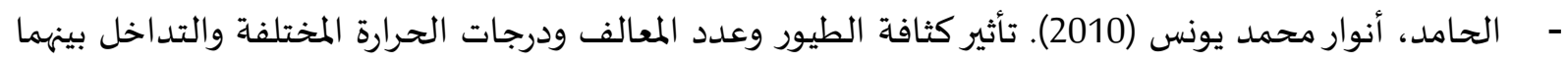
على بعض الصفات الإنتاجية والفسلجية لفروج اللحم. أطروحة دكتوراه، قسم الثروة الحيوانية، كلية الزراعة الثانة

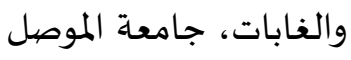
- الحامد، أنوار محمد يونس، أحمد محمد ثابت قاسم. (2019). تأثير استخدام الشاي الاخضر ( Camellia (Sinensis

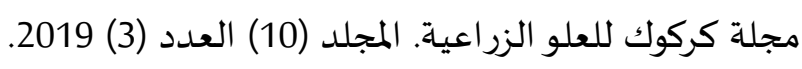

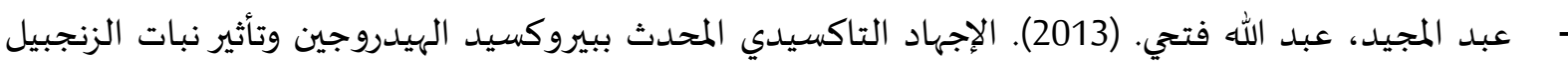
وفيتامين C في مستوى مضادات الأكسدة والأداء الفيزيولوجي والأداء الإنتاجي لطائر السلوى والنسل المسيديد الناتج.

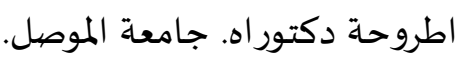

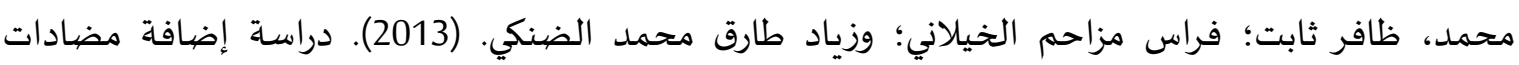

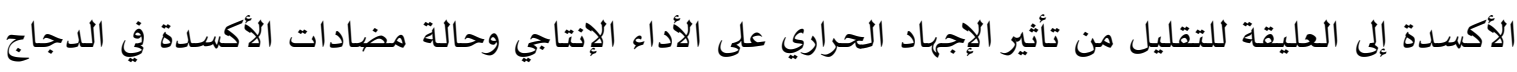
البياض البني. مجلة الانبارللعلوم البيطرية 6 (1): 96- 108. 


\section{ثانياً - المراجع بالإنجليزية:}

- Abdallah, O., Killany, O., El Gharib, H., \& Mohamed, R. (2016). Hematological and Growth Performance Studies after Withania Somnifera Supplementation in Broilers. Suez Canal Veterinary Medical Journal. SCVM), 21(1), 173-183.

- Adebiyi, O. A. (2011). Tocopherol supplementation on stocking density of broiler: effect on performance characteristics and serum enzymes. Tropical and subtropical agro ecosystems, 14 (2), 623-628.

- Adeyemo, G. O., Fashola, O. O., \& Ademulegun, T. I. (2016). Effect of stocking density on the performance, carcass yield and meat composition of broiler chickens. Biotechnology Journal International, 1-7.

- AL-Hamed. A. M. Y. (2021). Effect of different density and adding green tea in diet on productive characteristics, carcass and environmental content of intestines of quail. Indian Journal of Ecology (2021) 48 Special Issue (13): 65-71.

- Akotaker. MS, Surag. SM, Rekhate. DH, Dhok AP. Effect of supplementation of Ashwagandha (Withania somnifera) on performance of broilers. Indian Journal of Poultry Science. 2007; 42:92-94.

- Chung, T. H., \& Choi, I. H. (2016). Growth performance and fatty acid profiles of broilers given diets supplemented with fermented red ginseng marc powder combined with red koji. Brazilian Journal of Poultry Science, 18(4), 733-738.

- Chung SI, Rico CW, Kang MY. Comparative study on the poglycemic and ant oxidative effects of fermented paste (Doenjang) prepared from soybean and brown rice mixed with rice bran or red ginseng marc in mice fed with high fat diet. Nutrients 2014;6:4610-4624

- Choi, S. Y., Hong, H. D., Bae, H. M., Choi, C., \& Kim, K. T. (2011). Phytochemical characteristics of coffee bean treated by coating of ginseng extract. Journal of ginseng research, 35(4), 436. -441

- Cengiz, Ö., Köksal, B. H., Tatlı, O., Sevim, Ö., Ahsan, U., Üner, A. G., . \& \& Önol, A. G. (2015). Effect of dietary probiotic and high stocking density on the performance, carcass yield, gut micro flora, and stress indicators of broilers. Poultry science, 94(10), 2395-2403.

- Chikwa, K., Atkare, S. S., Bhardwaj, J. K., \& Nema, R. P. (2018). Herbal response of shatavari, ashwagandha root powder and vitamin E on performance of colour broilers. The Pharm Innovation Journal 2018; 7(8): 508-510

- Duncun, D. B. (1955). Multiple and multiple F test. Biometrics. 11:1-42.

- Durrani, F. R., Sultan, A., Ahmed, S., Chand, N., Khattak, F. M., \& Durrani, Z. (2007). Efficacy of Aniseed Extract as Immune Stimulant and Growth Promoter in Broiler Chicks. Pakistan journal of biological sciences, 10(20), 3718-3721 
- El-Gogary, M. R. and M. M. Azzam, 2014. Effects of dietary tryptophan levels and stocking density during the growing-finishing phase on broiler performance and immunity. Asian J. Anim. Vet. Adv., 9: 568-577

- Farhadi1. D and S. M. Hosseini. (2016). Evaluation of growth performance, carcass characteristics, litter quality and foot lesions of broilers reared under high stocking densities. Iranian Journal of Applied Animal Science (2016) 6(1), 187-194

- Houshmand, M., K. Azhar, I. Zulkifli, M. H. Bejo and A. Kamyab, 2012 Effects of prebiotic, protein level and stocking density on performance, immunity and stress indicators of broilers. Poult. Sci, 91: 393401

- Henrique. D. S., Oliveira. C., Ferreira., A. F. G., Silva. T. S.,, E. S., de Mello. B. F. F. R., de Freitas Andrade, A. Bruno, L. D. G. (2017). Effect of stocking density on performance, carcass yield, productivity, and bone development in broiler chickens Cobb 500®. Semina: Ciências Agrárias, 38(4), 2705-2717.

- Kim, HJ., Chae IG, Lee SG, Jeong HJ, Lee EJ, Lee IS. Effects of fermented red ginseng extracts on hyperglycemia in streptozotocin-induced diabetic rats. Journal of Ginseng Research 2010a;34:104112.

- Kim DC, In MJ. Production of hydrolyzed red ginseng residue and its application to lactic acid bacteria cultivation. Journal of Ginseng Research 2010;34:321-326.

- Li. X. M., Zhang. M. H., Liu. S. M., Feng. J. H., Ma. D. D., Liu. Q. X., Zhou. Y., Wang. X. J., Xing. S. (2019) Effects of stocking density on growth performance, growth regulatory factors, and endocrine hormones in broilers under appropriate environments. Poult. Sci, 98: 6611-6617

- Liu, H., Bai, S. P., Zhang, K. Y., Ding, X. M., Wang, J. P., Zeng, Q. F.,\& Su, Z. W. (2020). Effects of stocking density on the performance, tibia mineralization, and the expression of hypothalamic appetite genes in broiler chickens. Annals of Animal Science, 1(ahead-of-print).

- AL-Muslimawi, N. A., \& Ibrahim, D. K. Effect of early exposure to heat and addition of ginseng extract on production traits in broiler chicks Biochem. Cell. Arch. Vol. 19,No. 1, pp. 1683-1686, 2019

- Madilindi, M. A., Mokobane, A., Letwaba, P. B., Tshilate, T. S., Banga, C. B., Rambau, M. D., . . \& Benyi, K. (2018). Effects of sex and stocking density on the performance of broiler chickens in a sub-tropical environment. South African Journal of Animal Science, 48(3), 459-468.

- Nocerino, E., Amato, M., \& Izzo, A. A. (2000). The aphrodisiac and adapt genic properties of ginseng. Fitoterapia, 71, S1-S5.

- N. R. C. (1994). Nutrient of domestic animals. L. Nutrient Requirement of Poultry. Acad. Sci., Washington D. C.

- Uzum, M. H., \& Toplu, H. O. (2013). Effects of stocking density and feed restriction on performance, carcass, meat quality characteristics and some stress parameters in broilers under heat stress. Revue de Medecine Veterinaire, 164, 546-554. 
- OnbaŞılar. E. E., Poyraz. Ö. and S. Çetin. L. Effects of Breeder Age and Stocking Density on Performance, Carcass Characteristics and Some Stress Parameters of Broilers. Asian-Aust. J. Anim. Sci. Vol. 21, No. 2: 262 - 269 February 2008

- Rao. R. R., Platel. K., Srinivasan. K., (2003). In vitro influence of spices and spice-active principles on digestive enzymes of rat pancreas and small intestine. Nahrung 2003;47:408-412.

- Saha. M, Chowdhury. SD., Hossain. Md. E., Islam. Md. K., Roy. B. (2011) Organic water additive on growth performances, hematological parameters and cost effectiveness in broiler production. Journal of Animal Science and Technology 2011;53:517-523

- SAS Institute (2003). SAS User's guide statistic. SAS Inc. Cary NC.

- Sohaib, M., Butt, M. S., Shabbir, M. A., \& Shahid, M. (2015). Lipid stability, antioxidant potential and fatty acid composition of broilers breast meat as influenced by quercetin in combination with $\alpha$ tocopherol enriched diets. Lipids in Health and Disease, 14(1), 1-15

- Simsek, U. G., Ciftci, M., Cerci, I. H., Bayraktar, M., Dalkilic, B., Arslan, O., \& Balci, T. A. (2011). Impact of stocking density and feeding regimen on broilers: performance, carcass traits and bone mineralization. Journal of Applied Animal Research, 39(3), 230-233.

- Singh, V. P., Sahu, D. S., Kumar, S. H. A. L. U., \& Chauhan, S. H. (2017). Effect of dietary supplementation of ashwagandha (Withania somnifera), selenium and their combination on production performance of broiler chicks. Trends in Biosciences, 10(19), 3597-3602.

- Singh, M. K., Singh, V. P., Sahu, D. S., \& Jinu, M. (2017). Effect of dietary supplementation of Ashwagandha (Withania somnifera) and Selenium on growth performance and carcass quality of broilers. Asian Journal of Animal Science, 12(2), 129-133.

- Srivastava SB,Niwas R,Singh DP, Bisen B. Impact of herbal based diets on production efficiency of broiler. The Bioscan. 2013; 8(1):119-122.

- Sun, Z. W., Fan, Q. H., Wang, X. X., Guo, Y. M., Wang, H. J., \& Dong, X. (2018). High stocking density alters bone-related calcium and phosphorus metabolism by changing intestinal absorption in broiler chickens. Poultry science, 97(1), 219-226.

- Vasanthakumar. P., Pangayarselvi. B., Sasikumar. P., Chandrasekaran. D., Doraisamy. K. A.,. Purushothaman M. R. Performance of broilers fed ashwagandha (Withania somnifera) incorporated diets during summer season for alleviating heat stress. Indian J. Anim. Res., 49 (3) 2015: 333-335

- Qaid, M., Albatshan, H., Shafey, T., Hussein, E., \& Abudabos, A. M. (2016). Effect of stocking density on the performance and immunity of 1-to 14-d-old broiler chicks. Brazilian Journal of Poultry Science, 18(4), 683-692.

- Wang, B., Min, Z., Yuan, J., Zhang, B., \& Guo, Y. (2014). Effects of dietary tryptophan and stocking density on the performance, meat quality, and metabolic status of broilers. Journal of animal science and biotechnology, 5(1), 1-7. 
- Yıldırım, A., Şekeroğlu, A., Eleroğlu, H., Şen, M. I., \& Duman, M. (2013). Effects of Korean ginseng (Panax ginseng CA Meyer) root extract on egg production performance and egg quality of laying hens. South African Journal of Animal Science, 43(2), 194-207.

- Yokozawa, T., Satoh, A., \& Cho, E. J. (2004). Ginsenoside Rd attenuates oxidative damage related to aging in senescence-accelerated mice. Journal of pharmacy and pharmacology, 56(1), 107 